\title{
IDENTIDAD URBANA Y EL TURISMO DE EVENTOS DEPORTIVOS: EL GRAND DEPART TOUR DE FRANCIA 2015*
}

\author{
Juan Luis Paramio-Salcines** \\ Roberto Ruiz Barquín ${ }^{* * *}$ \\ Manuel Jesús Baena Arroyo****
}

\section{RESUMEN}

Ciudades de todo tipo en la actual jerarquía urbana se afanan por adquirir una nueva identidad. En ese proceso de reinvención urbana, el turismo de eventos deportivos ha venido desarrollando una gran capacidad para generar diferentes impactos 'tangibles' e 'intangibles', como se argumenta en este artículo con el caso de la ciudad holandesa de Utrecht y la organización del Grand Depart Tour de Francia 2015 (GDTF). Si bien se ha analizado de manera amplia el uso estratégico del Tour de Francia por parte de numerosas ciudades en la última década desde la perspectiva de la oferta, este estudio exploratorio con un carácter marcadamente internacional que incluye nueve países, uno de los cuales es España, examina el GDTF 2015 desde la perspectiva de la demanda. En particular, estudia los factores clave que pueden facilitar o condicionar el deseo de viajar, previamente al propio evento, de ciudadanos españoles a Utrecht, para seguir dicho evento. Con el fin de valorar el grado de conocimiento de los principales atractivos de la ciudad, así como las principales motivaciones de estos ciudadanos españoles a la hora de viajar a Utrecht

Recibido: 10 de febrero de 2016

Devuelto para su revisión: 17 de junio de 2016

Aceptado: 20 de octubre de 2016

* Este artículo es resultado del Proyecto de Investigación "Destination branding: The effect of the Tour of France organization on the image of the city of Utrecht around the world" e incluye los estudios de casos de nueve países (Alemania, China, España, Estados Unidos, Francia, Holanda, Italia, Japón y Reino Unido). El proyecto, financiado por la DeStad Utrecht (Ayuntamiento de Utrecht), fue dirigido por el Dr. Bob Heere, Universidad de Carolina del Sur, Estados Unidos durante el período 2014-15.

**Facultad de Formación del Profesorado y Educación. Departamento de Educación Física, Deporte y Motricidad Humana, Universidad Autónoma de Madrid, Ciudad Universitaria de Cantoblanco, C/Francisco Tomás y Valiente, 3, 28049, MADRID (España).E-mail: juanluis.paramio@uam.es

*** Facultad de Formación del Profesorado y Educación. Departamento Interfacultativo de Psicología Evolutiva y de la Educación, Universidad Autónoma de Madrid. E-mail: roberto.ruiz@uam.es

***** Departamento de Educación Física y Deportes, Universidad de Sevilla. E-mail: mbaena@us.es 
in situ, se han utilizado encuestas, un grupo de discusión y una revisión documental. El artículo concluye con los principales resultados que se derivan de las percepciones de los ciudadanos españoles de Utrecht y su relación con el GDTF 2015, además de las implicaciones prácticas de este caso.

Palabras clave: Identidad Urbana, Turismo de Eventos Deportivos, Turistas Deportivos, Gran Départ Tour de Francia 2015, Utrecht.

\title{
Identity of cities and event sport tourism: The Grand Depart Tour de France 2015
}

\begin{abstract}
All types of cities in the current urban hierarchy try their best to gain a new identity. In this process of reinventing cities, event sport tourism has potential to generate various tangible and non-tangible impacts as this article argues with the case of the Grand Depart Tour de France 2015 (GDTF) held in the city of Utrecht, the Netherlands. While the strategic use of the Tour de France by numerous cities in the last decade has been extensively analyzed from the supply perspective, this exploratory study, which is part of an international research project involving nine countries including Spain, examines this hallmark sport event from the demand perspective. Specifically, it analyzes the critical factors that might facilitate or constrain the intention, prior to the event, by Spanish citizens to travel to Utrecht to watch the event. Methodologically, this study is based on questionnaires, a focus group and literature review. This article concludes with the main results that emerge from the perceptions of Spanish citizens of Utrecht and its relation to the GDTF 2015 as well as the implications of this study.
\end{abstract}

Keywords: Urban Identity, Events Sport Tourism; Sport Event Tourists, Grand Départ Tour de France 2015, Utrecht.

\section{INTRODUCCIÓN}

El 'turismo de eventos deportivos' ${ }^{1}$ se ha consolidado como un producto turístico con capacidad para dinamizar el propio sector turístico en países y ciudades de todo tipo,

1 Desde una perspectiva académica-profesional, una de las tipologías más aceptadas para analizar las amplias sinergias que se generan entre el turismo y el deporte ha sido desarrollada por Gibson (1998, 2003) (véase Gibson y Fairley, 2014). Esta tipología que es aceptada por la National (leáse Norteamericana) Association of Sports Commissions (Schumacher, 2015), distingue entre: a) turismo activo (active sport tourism) que incluye a los turistas que viajan fuera de su lugar de residencia para realizar una práctica deportiva durante los períodos vacacionales, práctica que puede ser formal o informal, muy o poco activa y tener un grado de motivación desde competitiva a recreativa; b) turismo de eventos deportivos (event sport tourism) que agrupa a aquellos turistas que viajan fuera de su lugar de residencia para específicamente presenciar un evento deportivo. En este grupo, el componente turístico del usuario puede ser vario, desde casi inexistente, que implica únicamente presenciar el evento, hasta muy intenso donde, además de planificar el viaje para presenciar el evento, se aprovecha el viaje para visitar el lugar de destino y c) turismo deportivo que lleva a la nostalgia (nostalgia sport tourism) donde el turista se desplaza para visitar instalaciones históricas y museos relacionados con deportes y deportistas. Es importante considerar la relación con los destinos bajo la perspectiva del comportamiento y motivación del 
incluido España (Canadian Sport Tourism Alliance, 2012; Fernández Alles, 2014; Hosteltur, 2005; Jiménez Martín, 2011; Latiesa y Paniza, 2006; Llopis Goig, 2012; MECD, 2015a; Schumacher, 2015; UK Sport, 2015a,b; Visit Britain, 2015; Weed, 2008). Entre otros efectos, numerosas ciudades en la actual jerarquía urbana muestran un mayor interés por adquirir y proyectar una nueva y positiva imagen hacia el exterior. Esta evolución la explica con detalle Zukin et al., (1998:647) cuando afirman que 'el diseño actual ya no favorece la formación de zonas estancas y diferenciadas para el trabajo y el ocio, sino que toda la ciudad se dirige hacia el consumo de una imagen que es el principal valor que las ciudades poseen'. Los antecedentes de este proceso los encontramos en las respuestas que adoptaron ciudades norteamericanas a mediados del siglo pasado, entre otras: Detroit e Indianápolis, ante los profundos problemas urbanos, económicos y sociales iniciados por entonces (Henry y Paramio-Salcines, 1999; Paramio-Salcines, 2001, 2013). En busca de una nueva identidad, encontramos referencias generalistas que asocian a las ciudades, en palabras de Harvey (1990) como 'centros de entretenimiento y espectáculo'. Bajo este contexto, las ciudades necesitan diferenciarse unas de otras o seguir estrategias parecidas, pero de manera diferente. Ante esta tesitura, el evento deportivo puede ayudar en el proceso de redefinir la imagen de la ciudad o en su caso, en el fortalecimiento de la propia imagen de la ciudad. Prueba de lo expuesto, un número creciente de ciudades adoptan posicionamientos estratégicos diversos relacionados con los eventos como 'ciudad de eventos' (caso de Londres) (Smith, 2008); 'ciudad del deporte' (por ejemplo, Indianápolis, pionera en esta estrategia desde 1979, Barcelona, Fukuoka, Londres, Madrid, Sevilla, Sheffield, Melbourne, Toronto o Vancouver) (Henry y Paramio-Salcines, 1999; Paramio-Salcines, 2001, 2013); 'destino de turismo deportivo' (Higham, 2005; Waller, Trendafilova y Daniell, 2014; Weed y Bull, 2004) e incluso como 'ciudad para las bicicletas' (Berridge, 2012; Walker, 2015). Tal como abogan Álvarez del Blanco (1993), Green, Costa y Fitzgerald (2008) y Kavaratzis (2004), el marketing es clave para identificar y formular la imagen de la ciudad que se quiere promocionar a través de una amplia exposición mediática. Esto conlleva que la imagen debe ser cuidadosamente planificada, promocionada y comunicada tanto hacia el exterior, centrándose en colectivos como visitantes, inversores, deportistas, medios de comunicación, etc, pero sin obviar a los oriundos del lugar. Como se argumenta en este artículo con el caso de la ciudad holandesa de Utrecht y la organización del Grand Depart Tour de Francia 2015 (evento al cual nos referiremos con el acrónimo GDTF 2015), un evento anual global como el GDTF puede contribuir a fortalecer la imagen de la ciudad, así como fomentar la llegada de un mayor número de turistas.

Se espera que este fenómeno continúe su fase expansiva en las próximas décadas, superando todas las previsiones que dos pioneros en el estudio de las sinergias entre el turismo y el deporte como son Standeven y DeKnop (1999) aventuraban para finales del siglo XX. En nuestro país, Jiménez Martín (2011) y Latiesa y Paniza (2006) coinciden con las previsiones anteriores al subrayar el auge del turismo deportivo, a tenor de factores sociodemográficos, sociales, culturales y económicos. En el año 2013, la Organización Mundial del Turismo (en adelante OMT) resaltaba que el turismo deportivo suponía ya la

turista, así como los tres tipos de turistas deportivos que, en opinión de Weed y Bull (2004) y Weed (2008), catalogan como entusiastas, aversivos e indiferentes (veáse Latiesa y Paniza, 2006). Ambas tipologías son útiles para diseñar apropiadamente aquellas estrategias que permitan atraer más visitantes al destino. 
nada desdeñable cifra del 32\% de la industria turística global, aportándole 450.000 millones de euros, con un crecimiento del $14 \%$ y superando incluso al propio turismo que crece a un ritmo del 2-3\% (OMT, 2013, en Eapen, 2014:20). Para mantener ese dinamismo, la propia OMT iba más allá al sugerir que "los grandes acontecimientos deportivos han de ser concebidos y planificados por las ciudades como grandes acontecimientos turísticos" (en Hosteltur, 2005:6). Los eventos deportivos deben, por tanto, considerarse como un "producto turístico' con el fin de atraer a las ciudades de acogida a un segmento económicamente muy atractivo y con gran movilidad como el que representa el turista deportivo. El hecho más significativo no es, en sí mismo, lo que podemos denominar 'la globalización del turismo deportivo de eventos' sino el progresivo aumento tanto en valores absolutos como en porcentajes del número de turistas que justifican su viaje a cualquier lugar del mundo para asistir a acontecimientos deportivos. A esto se une que dicho segmento de turistas de eventos deportivos se caracteriza por su fidelidad al destino y por realizar un gasto medio superior que al que realiza el turista normal. Con respecto al impacto económico, Jiménez Martín (2011:185) estima que "el gasto medio diario que genera el turista de eventos deportivos es entre 4 y 6 veces superior al del turista medio".

Si bien, aunque como sugieren Robinson y Gammon (2004) existen múltiples motivaciones, primarias y secundarias, que impelen a un turista a desplazarse a un destino, es la propia asistencia al evento deportivo la que se consolida como factor clave a la hora de viajar (Gibson, Qi y Zhang, 2008; Higham, 2005; Latiesa y Paniza, 2006; Law, 2002; Standeven y DeKnop, 1999; Waller et al., 2014). Mientras esto ocurre en el plano individual, el atractivo del turismo deportivo de eventos no ha pasado desapercibido para numerosas ciudades que apuestan estratégicamente por todo tipo de eventos. Sin embargo, Smith (2008:4) nos recuerda que "muchas ciudades asumen que los eventos automáticamente generan una publicidad positiva, cuando las investigaciones muestran que los eventos pueden realmente generar una publicidad nada relevante e incluso en ocasiones, negativa". Es por ello que es clave seleccionar adecuadamente el evento como coinciden en señalar no solo la propia OMT sino una pléyade de autores (Masterman, 2009; Smith, 2008, 2012; Weed, 2008). Dicha selección del evento se debe valorar por las autoridades atendiendo a factores como: a) el número de personas (por ejemplo, deportistas, espectadores, medios de comunicación,..) que presumiblemente se desplacen debido al evento; b) la duración de su estancia en establecimientos hoteleros de diferente tipo y categoría; c) su nivel de gasto; d) el empleo generado; e) el grado de exposición mediática del evento y, por extensión, f) la promoción de la imagen de la ciudad (Green et al., 2008). De forma análoga al turismo donde se ha analizado con amplitud el concepto de imagen del destino, diferentes estudios constatan que en el sector del turismo deportivo existe una fuerte correlación entre la imagen que los posibles turistas tienen de la ciudad organizadora del evento y su decisión inicial de visitar dicho destino (Gibson, 2003; Gibson et al., 2008; Herstein y Berger, 2013; Kapladinou y Vogt, 2007; Kavaratzis, 2004; Waller et al., 2014; Wicker, Hallman y Zhang, 2012). A tenor de estos datos, en este artículo se argumenta que las autoridades deben examinar el evento desde la perspectiva de la demanda, analizando no sólo cuáles son los públicos objetivos y los factores clave de la oferta de las ciudades, sino que, sobre todo, se deben considerar las principales motivaciones por las que los futuros turistas deciden desplazarse a su lugar de destino, bien sea durante o incluso después del evento. 
Si bien algunas ciudades globales son ya destinos turísticos consolidados, estas mismas ciudades se promocionan como 'ciudad de eventos' (verbigracia, Londres). Dichas ciudades centran su interés en organizar aquellos eventos deportivos con una gran difusión mediática y significado cultural a escala global y que atraen a un importante flujo de visitantes. Valgan, a modo de ejemplo, los cuatro mega eventos deportivos por antonomasia: los Juegos Olímpicos, los Campeonatos del Mundo de Fútbol y de Rugby y la America's Cup. Estos mega eventos representan la parte más visible del turismo de eventos deportivos, pero no abordan todas las sinergias existentes entre el turismo, el desarrollo urbano y los eventos deportivos. Ante esta tesitura, otra pléyade de ciudades que compiten por organizar otros eventos, a priori, de menor nivel también tienen una gran repercusión a escala global, entre los que cabe destacar, los torneos de golf y de tenis, eventos automovilísticos (Henderson et al., 2010; Sánchez et al., 2013), campeonatos de vela, carreras populares, triatlones (IRONMAN series) o eventos ciclistas (la Vuelta a España o el Tour de Francia como se examina en este artículo).

Cuando se analiza dicho fenómeno en España, se observa como en las dos últimas décadas, ciudades y Comunidades Autónomas no han sido ajenas al potencial del turismo de eventos deportivos. A modo de ejemplo, encontramos desde grandes ciudades como Barcelona (Juegos Olímpicos y Paralímpicos de 1992) (Álvarez del Blanco, 1993, Barcelona Turisme, 2014), Madrid (candidaturas olímpicas de 2012, 2016 y 2020) (Paramio-Salcines, 2013), Sevilla (candidaturas olímpicas 2004, 2008 y 2012) o Valencia (America’s Cup 2007 y 2010) (Llopis Goig y García Alcober, 2012) hasta ciudades más pequeñas como Jerez de la Frontera (Gran Premio de Motociclismo de España 2013) (Fernández Alles, 2014), Orense (Rally de Orense) (Sánchez et al., 2013), Lanzarote (Ironman Club La Santa) o Tarragona (Juegos del Mediterráneo 2017) (Año et al., 2013). Barcelona es un referente mundial a la hora de promocionarse interna y externamente como 'ciudad del deporte', con la organización de un amplio portafolio de eventos de carácter nacional e internacional ${ }^{2}$ (entre los que se incluye la organización de una etapa del Tour de Francia en su edición de 2009). Si bien previamente a la organización de los Juegos Olímpicos de 1992, la ciudad sólo era capaz de atraer a 1,73 millones de turistas (1990), tras la celebración de dicho megaevento, Barcelona ha ido gradualmente consolidándose como un destino turístico consolidado con reconocimiento internacional. Prueba de ello es que es la sexta ciudad más visitada en Europa (tras Londres, París, Berlín, Roma y Madrid) con la llegada de 7,8 millones de turistas en el año 2014, de los cuales el $80 \%$ son extranjeros (Barcelona Turisme, 2014). Incluso el denominado 'turismo deportivo que lleva a la nostalgia' y cuyo máximo exponente en la ciudad es el Museo del FC Barcelona atrae regularmente a más de 1.5 millones de visitantes. En Jerez, la organización del Gran Premio de Motociclismo en la ciudad en su edición de 2013 estima Fernández Alles (2014) que el impacto económico en Andalucía fue de 100 millones de euros, con un gran potencial para atraer a casi 220.000 visitantes a la ciudad durante los tres días del evento, cifra que supera en un 19,9\% a los obtenidos en la edición de 2012. Pero no podemos de dejar de mencionar el Ironman La Santa Sport

2 Para consultar la oferta de eventos deportivos que organiza la ciudad de Barcelona, véase http:// bcnsports.barcelonaturisme.com/ 
que se viene celebrando ininterrumpidamente en Lanzarote desde el año 1992. De este evento, cabe destacar que es el más antiguo de Europa y el segundo más antiguo de las series IRONMAN. Prueba de su potencial económico, deportivo y turístico es que este evento (en su edición $\mathrm{n}^{\circ} 26$ celebrada el 21 de mayo de 2016) es capaz de atraer no sólo a más de 2.000 atletas sino que además se beneficia de la asistencia de 6.500 acompañantes, que suelen estar en la isla y en los pueblos del recorrido una media de 7 a 10 días. De igual modo, un número amplio de Comunidades Autónomas, tradicionalmente turísticas como Andalucía, Cataluña, Islas Baleares, Valencia, Islas Canarias, Castilla León o Murcia (Cardenal, 2016; Fernández Alles, 2014; Jiménez Martín, 2011; Latiesa y Paniza, 2006; Peñalver Torres, 2004), se promocionan como 'destinos de turismo deportivo'. Con el objetivo doble de desestacionalizar el destino y diversificar su oferta turística, combinan tanto una extensa oferta de deportes (turismo activo) como de eventos deportivos (turismo de eventos deportivos). Traemos a colación las palabras del presidente del Consejo Superior de Deportes, Miguel Cardenal, cuando afirmaba en enero de 2016 que "La Región de Murcia lo tiene todo para convertirse en una de las referencias del turismo deportivo" y que "su programa "La Región de Murcia, destino deportivo" se alinea con el programa del Gobierno, que apuesta por que el deporte genere recursos, resaltando los numerosos turistas que viajan a España para practicar deporte o asistir a eventos deportivos" (Cardenal, 2016; véase Peñalver Torres, 2004 donde explica la apuesta por el turismo activo de la Región de Murcia).

Si aludíamos al Tour de Francia como ejemplo paradigmático de un gran evento, dicha valoración se sustenta en los siguientes datos: a) es la prueba ciclista por etapas más antigua (creada en julio de 1903) y más relevante a escala mundial; b) es el tercer evento con más cobertura mediática global; c) es un evento anual que no se relaciona exclusivamente con una ciudad y en nuestro caso, d) por ser un producto turístico de primera magnitud con capacidad suficiente para asociar la marca "Tour de Francia" al nombre de la ciudad (Balduck, Maes y Buelens, 2011; Dauncey y Hare, 2003; Grand Départ Official Programme, 2015; Leblanc, 2005; Lovell, 2008; Smith, 2008). Durante las dos últimas décadas (la primera con Jean Marie Leblanc, director de la prueba ciclista entre 1989 y 2005, y actualmente con Christian Prudhomme) se ha intensificado el proceso de internalización del evento, que incluye, entre otras innovaciones, la organización de etapas prólogo y otras etapas en países limítrofes. El propio Leblanc cuantificaba por el año 2005 en más de 100 candidaturas que incluían un gran número de ciudades francesas y de otros países que competían por albergar etapas de la prueba (Leblanc, 2005). Por aquel entonces, Leblanc ya subrayaba el posicionamiento estratégico del Tour de Francia como producto turístico (en la línea que sugiere la OMT) cuando afirmaba que 'un gran evento deportivo como el Tour de Francia ha logrado convertirse en un producto turístico de primer orden' (Leblanc, 2005:73) al conseguir una gran afluencia de turistas nacionales y extranjeros en un mes vacacional como julio. Su ubicación temporal representa un hecho diferencial con respecto a otras grandes vueltas, lo que le ha permitido mantenerse como un evento muy atractivo para infinidad de ciudades. La empresa Amoury Sport Organisation (ASO), propietaria de los derechos organizativos de esta prueba ciclista y de otros eventos como el Rally París Dakar, los maratones de París y Barcelona, pruebas ciclistas como la París-Roubaix, la París-Niza e incluso es 
accionista de la Vuelta a España, asume las siguientes competencias: a) la selección de las ciudades que albergarán las etapas de cada edición del Tour; b) el diseño del formato del Tour; c) la exposición mediática del evento; y d) la optimización de los recursos provenientes del evento. Para la edición del 2015, la empresa ASO concedió a Utrecht el derecho a organizar el GDTF desde el 1 al 5 de julio, período que incluye la presentación de los equipos, la etapa prólogo con una contrarreloj individual y el inicio de la segunda etapa.

El uso estratégico del "Tour de Francia" ha atraído también el interés de académicos en fechas recientes. El foco de atención de la mayor parte de los estudios se centra en analizar los impactos económicos, sociales, deportivos y turísticos del propio evento en los destinos desde la perspectiva de la oferta y en las percepciones de los propios residentes ante la celebración del evento (Balduck et al., 2011; Berridge, 2012; Bull y Lovell, 2007; Lovell, 2008; Smith, 2008), pero hay escasos estudios que lo examinen desde la perspectiva de la demanda. Este estudio exploratorio contribuye a expandir aquellos que analizan los factores clave que puedan facilitar o condicionar el deseo de viajar de ciudadanos españoles a Utrecht para seguir el GDTF 2015. Partiendo de esta premisa, el objetivo de este estudio incide en conocer, previamente a la celebración del evento, cuál era el grado de conocimiento y valoración que los ciudadanos españoles tenían de los principales atractivos de la oferta turística, cultural y deportiva de Utrecht. El resto del artículo se estructura de la siguiente forma. A continuación, se aborda el potencial del sector del turismo de eventos deportivos a escala nacional e internacional. El siguiente apartado se centra en el estudio del potencial de dicho sector como estrategia competitiva de ciudades desde un punto de vista internacional. En el cuarto epígrafe, se analiza el origen del interés y las razones esgrimidas por parte de las autoridades para organizar el GDTF 2015. En el quinto, se expone la metodología de elaboración de la encuesta y del grupo de discusión en los que se basan los resultados presentados. El análisis que se presenta se basa en la combinación de una metodología cuantitativa que incluye la recogida y análisis de una muestra de 488 cuestionarios (modelos A y B) realizados en diferentes ciudades de España en el período de enero hasta marzo de 2015 complementado con un grupo de discusión con seis participantes realizado el 16 de abril de 2015. El análisis se ha ampliado con la revisión de datos estadísticos, informes y publicaciones sobre el turismo de eventos deportivos, documentos realizados por los organizadores de la prueba ciclista implicados en el proceso así como el grado de cobertura de diferentes medios de comunicación sobre el evento en sí mismo. El artículo concluye con los principales resultados que se derivan de cómo ven los ciudadanos españoles Utrecht y su relación con GDTF 2015 así como un apartado final de conclusiones e implicaciones prácticas del caso estudiado.

\section{EL SECTOR DEL TURISMO DE EVENTOS DEPORTIVOS A ESCALA NACIONAL E INTERNACIONAL}

Con el objeto de valorar el alcance real del sector del turismo de eventos deportivos a escala nacional e internacional, traemos a colación una serie de indicadores que nos pueden ayudar en este propósito. Sin pretender ser exhaustivos, podemos señalar su 
contribución a la economía local, regional y nacional, el número de turistas nacionales e internacionales y el gasto atribuible a dichos turistas asociados al evento, la estimación de la ocupación hotelera asociada al evento, su contribución a la transformación físicaurbanística de las ciudades, el número de empleos directos e indirectos creados o por el grado de visibilidad y la promoción turística nacional e internacional de la ciudad. Algunos de estos impactos mencionados son más fáciles, entre otros, de cuantificar, pero otros (la promoción turística del destino y la proyección de una imagen) son más difíciles de estimar y requieren de estudios longitudinales.

Como prototipo de la globalización del turismo de eventos deportivos, destaca un país como el Reino Unido que goza de una dilatada historia en la organización de eventos deportivos y, sobre todo, sobresale por haberlos incorporado de forma prioritaria en sus políticas urbanas y deportivas, principalmente por su impacto económico y por su capacidad para promover grandes cambios urbanísticos (Smith, 2012). No menos importante es por su potencial para atraer la llegada de turistas de otros países (UK Sport, 2015a,b; Visit Britain, 2015). En términos globales, los eventos deportivos contribuyen con más de 15.000 millones de libras ( $€ 20.763$ millones) por año al turismo del país (DCMS, 2015). Centrándonos en un evento anual como la Premier League, no sólo concita el interés obvio de innumerables aficionados al fútbol del país en cuestión, sino que fue capaz de atraer a más de 800.000 visitantes de otros países a sus estadios en el año 2014. Este volumen de turistas demuestra la capacidad de atracción de un evento. Y, sobre todo, este evento anual tuvo una traslación económica con un gasto total estimado de 684 millones de libras (951 millones de euros) y con un gasto medio por visitante de 855 libras (1.189 euros) durante su estancia (media de 10.4 noches), superior al gasto medio de un turista tradicional que visita el país (636 libras (905 euros)), según señala el informe Football tourism scores for Britain (Visit Britain, 2015; véase también Eapen, 2014). Pero si el caso de la Premier League es paradigmático, eventos como los Juegos Olímpicos y Paralímpicos de Londres 2012 o, más recientemente, el Campeonato del Mundo de Rugby 2015 han constituido otro punto de inflexión en el uso estratégico de los eventos. La Oficina de Estadísticas del Reino Unido estima que el país recibió la nada despreciable cifra de 698.000 visitantes para seguir en directo los Juegos Olímpicos y Paralímpicos de 2012 (Office for National Statistics, 2013). No menos importante ha sido el Campeonato del Mundo de Rugby 2015 con la llegada estimada de más de 466.000 turistas durante su celebración y con un gasto estimado de 869 millones de libras (1.201 millones de euros) (Ernst \&Young, 2014). Pero esta apuesta no acaba ahí si consideramos que el país ha conseguido organizar más de 70 eventos deportivos de carácter internacional en la última década, entre los que destacan eventos ciclistas como el GDTF 2007 en Londres, Canterbury y Kent y el GDTF 2014 en York. En los próximos años, el país organizará el Campeonato del Mundo de Atletismo 2017 o la Copa del Mundo de Cricket 2019, como se recoge en el programa Gold Event Series (UK Sport, 2015a,b). En términos generales, el UK Sport planea invertir más de 50 millones de libras (70.7 millones de euros) hasta el año 2023, con el objetivo de adquirir los derechos de más de 100 eventos. Con esta iniciativa, el gobierno espera conseguir un impacto económico estimado en diez veces superior a la inversión (más de 500 millones de libras ( $€ 700$ millones)). Datos que prueban que los eventos son, sin lugar a dudas, claros exponentes del potencial del turismo de eventos deportivos y del impacto de los 
turistas deportivos en la economía del país ${ }^{3}$. Sin abandonar el Reino Unido, encontramos que no sólo destaca por su capacidad para atraer a un gran número de turistas foráneos asociados al turismo de eventos deportivos, sino que también es uno de los principales países emisores tanto de turistas de eventos como de turismo activo. De este fenómeno se beneficia España, con la llegada masiva de nuestro principal nicho de mercado como son los turistas británicos, estimándose que uno de cada cuatro turistas que recibe nuestro país proceden de dicho país.

Pero el Reino Unido no es un caso aislado porque sobresalen otros países tradicionalmente turísticos como Estados Unidos, líder mundial en la organización de eventos deportivos, que recibió más de 25,6 millones de turistas deportivos con un gasto total de 8.960 millones de dólares en el año 2014 (Schumacher, 2015). Otro país significativo es Canadá que organiza aproximadamente 200,000 eventos de todo tipo anualmente; eventos que generan 5.200 millones de dólares canadienses provenientes de turistas canadienses y de otros países asociados en el año 2014. Este sector ha experimentado el mayor crecimiento de la industria turística desde el año 2006 (Canadian Sport Tourism Alliance, 2014). A este interés por los eventos deportivos se suman grandes mercados emergentes como los países denominados BRICS (acrónimo de Brasil (Campeonato del Mundo de Fútbol de 2014 o los Juegos Olímpicos y Paralímpicos de 2016), Rusia, India, China y Sudáfrica), Qatar o recientemente Azerbaiyán (European Games 2015 celebrados en Bakú) (Eapen, 2014). No podemos perder de vista el caso de nuestro país, como se analiza a continuación.

España, un país turístico por excelencia y considerado el segundo del mundo con más ingresos por el turismo internacional y el primero de Europa en donde el turismo supone el 13,5\% del empleo total de la economía (Instituto de Estudios Turísticos, 2011), el turismo activo y el turismo de eventos deportivos solo han comenzado a ser valorados como dinamizadores del turismo en nuestro país en la última década (Fernández Alles, 2014; Jiménez Martín, 2011; Llopis Goig, 2012; Peñalver Torres, 2004). Esta situación ha revertido si acudimos a los datos oficiales disponibles en el año 2013 que muestran que el conjunto de los turistas residentes en España realizaron 2.863,2 miles de viajes asociados al turismo activo con un gasto turístico total de 583,1 millones de euros, mientras que el turismo activo que realizan los turistas extranjeros que nos visitan (estimado en más de 9 millones) desempeña un papel clave en la potenciación del turismo nacional con un gasto total de 9.821.603.807 euros (MECD, 2015a). Como se desprende de los datos (tabla 1), el turismo activo es también un sector muy pujante donde los turistas extranjeros que nos visitan, nuestro principal público objetivo, se decantan principalmente por la realización de deportes náuticos y senderismo-montañismo, seguido por la práctica del golf junto con la asistencia a eventos como se recoge en la tabla ya mencionada. Los deportes mencionados junto con la asistencia a eventos deportivos son valorados positivamente por Jiménez Martín (2011) como una 'oferta físico-deportiva de alto impacto económico'. Bajo el epígrafe "asistencia a

3 Prueba de la importancia del sector de eventos deportivos en el Reino Unido, el Departamento de Cultura, Media y Deporte (Department of Culture, Media and Sport) junto con un organismo deportivo como el UK Sport y otras organizaciones relacionadas con el turismo (Visit Britain o Event Scotland), entre otras, han desarrollado un herramienta denominada "eventIMPACTS" con el objetivo de facilitar a cualquier organizador de eventos público o privado la estimación de los impactos sociales, económicos, medioambientales y de las redes sociales asociado a la organización de eventos deportivos y culturales (véase en http://www.eventimpacts.com/). 
espectáculos deportivos", el Instituto de Turismo de España resalta la importancia del sector del turismo de eventos deportivos (MECD, 2015b). De tal forma que casi dos millones de turistas no residentes en España (1.900.831) nos visitaron para asistir a eventos deportivos en el año 2014, con un gasto total de 2.467 millones de euros. De forma paralela, los propios turistas residentes realizaron 314.834 viajes para presenciar eventos, otro grupo con gran potencial de crecimiento (Tabla 2).

\section{Tabla 1}

\section{ENTRADA Y GASTO TOTAL DE TURISTAS NO RESIDENTES QUE PRACTICARON DEPORTES RELACIONADOS CON EL TURISMO ACTIVO Y EL TURISMO DE EVENTOS DEPORTIVOS CON DESTINO ESPAÑA EN EL AÑ 2014}

\begin{tabular}{|c|c|c|c|c|}
\hline & Turistas & $\begin{array}{l}\text { \%Variación } \\
\text { interanual }\end{array}$ & Gasto total & $\begin{array}{l}\text { \%Variación } \\
\text { interanual }\end{array}$ \\
\hline Practicó actividades deportivas & 9.248 .495 & 11,2 & 9.821 .603 .807 & 10,7 \\
\hline Golf & 986.244 & $-3,7$ & 1.269.368.599 & $-3,7$ \\
\hline Esquí - nieve & 142.646 & 94,1 & 165.540 .028 & 121,5 \\
\hline Deportes náuticos & 3.028 .555 & 12,0 & 3.012 .192 .233 & 8,9 \\
\hline \multicolumn{5}{|l|}{ Caza } \\
\hline Senderismo, montañismo & 3.090 .309 & 10,2 & 3.073 .519 .512 & 9,4 \\
\hline Deporte de aventura & 502.849 & 39,3 & 531.158 .533 & 52,0 \\
\hline Otros deportes & 4.558 .898 & 15,2 & 4.935 .941 .430 & 13,8 \\
\hline Asistencia a espectáculos deportivos & 1.900 .831 & 18,5 & 2.467 .465 .650 & 22,5 \\
\hline Actividades culturales & 36.403 .932 & 11,4 & 39.111 .281 .050 & 11,3 \\
\hline Visitas culturales & 33.414 .666 & 13,3 & 36.309.193.894 & 13,3 \\
\hline Asistencia a espectáculos culturales & 5.955 .088 & 2,9 & 8.498.253.389 & 10,2 \\
\hline Otras actividades culturales & 12.320 .012 & $-13,3$ & 15.268.423.391 & $-8,6$ \\
\hline $\begin{array}{l}\text { Servicios del tipo balnearios, } \\
\text { talasoterapia }\end{array}$ & 2.426 .111 & 7,0 & 2.911.336.443 & 5,0 \\
\hline Visitas a parques temáticos & 7.401 .534 & 14,6 & 7.765.030.009 & 9,8 \\
\hline Visitas a casinos, salas de juego & 849.860 & 36,8 & 1.104.475.328 & 42,6 \\
\hline $\begin{array}{l}\text { Actividades gastronómicas: } \\
\text { alta gastronomía, visitas a bodegas, } \\
\text { etc. }\end{array}$ & 9.491 .286 & 28,6 & 10.675.127.953 & 23,8 \\
\hline $\begin{array}{l}\text { Actividades de diversión (discotecas, } \\
\text { clubes) }\end{array}$ & 13.632 .472 & 12,9 & 14.601.499.015 & 12,9 \\
\hline Visitas a familiares & 6.866 .779 & 9,1 & 5.630 .741 .803 & 2,7 \\
\hline Realizan compras & 43.686 .921 & 6,4 & 47.119.342.585 & 5,9 \\
\hline No realiza actividades & 7.491 .796 & $-4,9$ & 5.094 .863 .727 & $-6,3$ \\
\hline Total general & 64.995 .283 & 7,1 & 63.093.626.606 & 6,5 \\
\hline
\end{tabular}

Fuente: Comunicación personal del Instituto de Turismo de España (20 de Agosto de 2015) proveniente de Egatur (2014). Nota: Las celdas en blanco responden a una insuficiente base muestral (inferior a 100 registros) 
Tabla 2

NÚMERO DE VIAJES DE LOS TURISTAS RESIDENTES SEGÚN DESTINO INTERNO Y EMISOR, SEGÚN ACTIVIDADES EN EL AÑO 2014

\begin{tabular}{|c|c|c|c|c|c|c|}
\hline & \multicolumn{6}{|c|}{$\mathbf{N}^{0}$ Viajes } \\
\hline & \multicolumn{2}{|c|}{ Turismo interno } & \multicolumn{2}{|c|}{ Turismo emisor } & \multicolumn{2}{|c|}{ Total Destino } \\
\hline & $\mathrm{N}^{o}$ de Viajes & $\begin{array}{c}\% \\
\text { V.I.V. }\end{array}$ & $\mathrm{N}^{\mathrm{o}}$ de Viajes & $\begin{array}{c}\% \\
\text { V.I.V. }\end{array}$ & $\mathrm{N}^{\mathrm{o}}$ de Viajes & $\begin{array}{c}\% \\
\text { V.I.V. }\end{array}$ \\
\hline Actividades & 31.955 .623 & $-6,6$ & 5.856 .028 & 1,4 & 37.811 .651 & $-5,5$ \\
\hline Compras & 20.809 .777 & 1,0 & 4.497 .997 & 8,0 & 25.307 .774 & 2,2 \\
\hline Deportes & 4.344 .599 & $-25,6$ & 566.753 & $-27,1$ & 4.911 .352 & $-25,7$ \\
\hline \multicolumn{7}{|l|}{ Caza } \\
\hline Deportes al aire libre & 3.098 .480 & $-13,4$ & 310.177 & $-17,0$ & 3.408 .657 & $-13,7$ \\
\hline Deportes de nieve & 252.648 & $-23,7$ & & & 382.773 & $-26,6$ \\
\hline \multicolumn{7}{|l|}{ Deportes de riesgo } \\
\hline Deportes náuticos & 1.054 .321 & $-39,6$ & 129.011 & $-29,9$ & 1.183 .333 & $-38,7$ \\
\hline \multicolumn{7}{|l|}{ Golf } \\
\hline Otros Deportes & 332.097 & $-31,0$ & & & 366.712 & $-34,8$ \\
\hline \multicolumn{7}{|l|}{ Pesca } \\
\hline Gestiones Administrativas & & & & & 145.662 & $-48,7$ \\
\hline Visita a familia y amigos & 16.214 .182 & $-7,5$ & 1.879 .730 & $-6,4$ & 18.093 .912 & $-7,4$ \\
\hline Espectáculos deportivos & 314.834 & $-31,4$ & & & 427.657 & $-25,3$ \\
\hline Espectáculos culturales & 5.428 .563 & $-2,8$ & 1.796 .109 & 9,7 & 7.224 .672 & 0,0 \\
\hline Visitas culturales & 16.528 .937 & 0,2 & 4.783 .092 & 3,6 & 21.312 .029 & 0,9 \\
\hline Visitas parques temáticos & 945.160 & $-24,7$ & 328.485 & $-28,4$ & 1.273 .645 & $-25,7$ \\
\hline Juegos de azar & & & & & 177.108 & 14,1 \\
\hline \multicolumn{7}{|l|}{ Congresos y reuniones } \\
\hline Disfrute y uso de la playa & 15.097.238 & 0,2 & 1.456 .095 & 2,5 & 16.553 .333 & 0,4 \\
\hline Servicios de tipo balneario & 597.525 & $-34,9$ & 334.155 & $-12,4$ & 931.680 & $-28,3$ \\
\hline Acontecimientos religiosos & 1.842 .549 & $-33,7$ & 390.938 & $-27,4$ & 2.233 .487 & $-32,7$ \\
\hline Actividades gastronómicas & 21.238 .459 & 1,5 & 4.261 .708 & 4,5 & 25.500 .168 & 1,9 \\
\hline Salir de copas & 10.335.302 & $-10,8$ & 2.223 .638 & 2,2 & 12.558 .940 & $-8,7$ \\
\hline Pasear por el campo & 16.936 .374 & 2,8 & 2.550 .458 & 10,4 & 19.486 .832 & 3,8 \\
\hline
\end{tabular}

Fuente: Comunicación personal del Instituto de Turismo de España (20 de Agosto de 2015) proveniente de Turespaña, SGCET, Familitur (Estadística de Movimientos Turísticos de los Españoles)

Nota: Las celdas en blanco responden a una insuficiente base muestral (inferior a 100 registros)

* \% V.I.V.: Variación interanual Viajes.

\section{EL TURISMO DE EVENTOS DEPORTIVOS COMO POSICIONAMIENTO ESTRATÉGICO DE LAS CIUDADES}

Ante las perspectivas optimistas que vaticina la OMT y diferentes autores sobre el turismo deportivo para los años venideros, no es de extrañar que exista un mayor interés 
por su estudio a escala internacional. Valga como muestra las palabras de Weed (2008: 14) que constató que "un $42 \%$ de los artículos publicados en el período 2000-2003 en las principales (53) revistas del área de deporte, turismo y ocio se centra en el 'turismo de eventos deportivos"'. Y de los estudios que examinan los eventos deportivos en las ciudades predominan aquellos de tipo descriptivo y que evalúan principalmente los impactos económicos (Higham, 1999), seguidos, a cierta distancia, por otros que analizan los impactos sociales, psicológicos y deportivos y en menor medida, los simbólicos (imagen e identidad) para las ciudades, sus ciudadanos y sus posibles visitantes. Ante esta realidad, un número cada vez mayor de autores abogan por realizar estudios explicativos que permitan avanzar en la construcción de una agenda específica de investigación del sector del turismo de eventos deportivos (Ashworth y Page, 2011; Getz, 2008; Gibson, 2003; Higham, 2005; Law, 2002; Weed y Bull, 2004; Weed, 2008). No es de extrañar que sea cada vez más necesario realizar investigaciones que permitan identificar los mercados a los cuales se pueden dirigir las campañas de marketing con el objetivo de consolidar la imagen de una ciudad, como representa el caso de Utrecht con el GDTF 2015. Y no menos importante, otro aspecto reside en conocer las necesidades y demandas de los diferentes tipos de turistas deportivos así como conocer las motivaciones por los cuales se desplazarían o no a la ciudad bien sea antes, durante o después del evento (Getz, 2003, 2008; Gibson et al., 2008; Jiménez Martín, 2011; Latiesa y Paniza, 2006; Robinson y Gammon, 2004; Sánchez et al., 2013; Weed y Bull, 2004). No debemos de olvidar que uno de los indicadores del éxito socio-económico de un evento deportivo radica en su capacidad para atraer nuevos turistas y de estimular el gasto económico en el lugar.

Los líderes valoran los eventos deportivos, como es el caso del GDTF 2015 en Utrecht, por su potencial para alcanzar diferentes objetivos, no excluyentes y en ocasiones complementarios; entre los que se incluyen objetivos de índole económico, social, urbanístico, turístico, deportivo y simbólico. En la mayoría de ocasiones, el discurso oficial hace especial énfasis en la organización de eventos como una estrategia de desarrollo económico y por su innegable contribución a acelerar procesos de regeneración físico-económica de las propias ciudades. Ese mismo discurso oficial resalta los beneficios que, directa o indirectamente, redundarán positivamente en determinados sectores productivos de la ciudad (hotelero, restauración, transporte...) y por extensión, en los propios residentes, la capacidad para atraer un número elevado de turistas deportivos nacionales e internacionales o como medio para incrementar los niveles de práctica deportiva de la población en general y de 'grupos prioritarios' en particular. Como hemos comentado en la introducción, existe otro legado intangible simbólico asociado al evento, no menos importante, que es la promoción de una nueva imagen internacional de la ciudad. Como ya se comentó anteriormente, el caso de España sirve para ilustrar los procesos anteriormente mencionados. La propia naturaleza abierta del deporte ofrece amplias posibilidades para innovar en el sector de los eventos. Planteamiento que ha sido seguido por una de las ciudades más activas en este sector como es Barcelona con la creación y organización de un 'evento autogenerado' como la Barcelona Duo World Race en 2007. En la línea de lo expuesto por Zukin et al., la imagen de la ciudad virtual precede a la imagen real de la ciudad, por lo que el evento anteriormente mencionado forma parte del posicionamiento de la ciudad como un destino turístico de primera magnitud, así como para abrirse a nuevos mercados. 
Si bien la mayor parte de los estudios glosan los efectos positivos de los eventos, otros estudios resaltan que la organización de eventos deportivos, en determinados casos, conllevan importantes costes para las ciudades organizadoras y, por ende, para sus ciudadanos. Un ejemplo paradigmático es la ciudad de Atenas, sede de los Juegos Olímpicos de 2004. Es precisamente en el contexto norteamericano donde existe un amplio debate sobre la utilización y financiación pública de eventos deportivos por parte de sus ciudades; debate que se ha extendido al mundo académico con autores tomando posturas encontradas ante el fenómeno descrito. En ocasiones, las previsiones que se realizan sobre el impacto económico en la ciudad suelen ser excesivamente optimistas o los costes pueden superar a los beneficios. Entre los costes, por ejemplo, se citan el incremento del déficit público a resultas de la gestión deficiente del evento, congestiones de tráfico debido a la organización del evento, la disminución del gasto en servicios públicos básicos, el desplazamiento de ciudadanos de ciertas áreas de la ciudad durante el evento o la falta de ingresos por la gestión de las instalaciones que se utilizan para el evento (Law, 2002; Paramio-Salcines, 2013).

Dichos datos están sujetos a variaciones a la hora de cuantificar los beneficios y los costes para la ciudad organizadora y sus ciudadanos. Y como ya se comentó, son precisamente los beneficios sociales y simbólicos que los eventos deportivos promueven los más difíciles de evaluar. En ese sentido, escasean los estudios que evalúen si realmente se consiguen dichos beneficios para la ciudad organizadora y sus ciudadanos. Y es precisamente en relación con la organización de etapas del Tour de Francia en ciudades belgas como Gante (Balduck et al., 2011) e inglesas como Londres y Canterbury (Berridge, 2012; Bull y Lovell, 2007; Lovell, 2008; Social Science Research, 2007; Smith, 2008) donde encontramos estudios que examinan las valoraciones de los residentes. Así, Balduck et al., (2011) analizaron las valoraciones de los ciudadanos de Gante con la llegada de una etapa a la ciudad en la edición de 2007. De forma análoga al caso de Utrecht, Berridge (2012), Smith (2008) y Social Science Research (2007) se han centrado en el GDTF 2007 en Londres (que entre otros impactos positivos consiguió atraer entre 900.000 y 1.4 millones de espectadores e impulsar el uso masivo de la bicicleta en la ciudad) y en otras localidades periféricas por donde pasaba dicha edición como Deptford (sureste de Londres). Adicionalmente, Bull y Lovell (2007) y Lovell (2008) examinaron el proceso de planificación y gestión ocasionado con la llegada de la primera etapa del GDTF 2007 en Canterbury. En España, han continuado esta línea de investigación autores como Año et al., (2013) con los Juegos Mediterráneos de Tarragona que se celebrarán en el año 2017 y Llopis Goig y García Alcober (2012) con la America's Cup en Valencia.

Otras líneas de investigación que han sido escasamente estudiadas son, por un lado, las que analizan las características de los turistas deportivos y por otro, las que determinan cuáles son los factores clave de la oferta de las ciudades junto con las motivaciones que hacen que potenciales visitantes se decidan a viajar a aquellas ciudades que acogen eventos (Higham, 2005; Kaplanidov y Vogt, 2007; Latiesa y Paniza, 2006; Law, 2002; Robinson y Gammon, 2004; Smith, 2008, 2012; Weed y Bull, 2004; Wicker et al., 2012). Con respecto a esta segunda área, a pesar de la gran diversidad de motivaciones, primarias y secundarias, para realizar un viaje asociado a un evento deportivo, Law (2002) jerarquiza y diferencia entre atractivos primarios, secundarios y adicionales de la ciudad. Los factores primarios 
constituyen las principales motivaciones que justificarían el viaje de cualquier turista, entre los que se incluiría, sin un orden jerárquico, una amplia oferta de equipamientos culturales (museos y galerías de arte, teatros,...), instalaciones arquitectónicas deportivas cubiertas y al aire libre, equipamientos para el entretenimiento (casinos, festivales..), y otros atractivos relacionados con el ocio (que incluye aspectos físicos (atributos históricos de edificios emblemáticos, zonas de la ciudad, barrios, parques y zonas verdes, canales y zonas de agua, puertos...) y socio culturales (historia y cultura local, grado de hospitalidad del lugar y de sus ciudadanos, seguridad....). Law (2002) y Wicker et al., (2012) coinciden a la hora de destacar otros factores secundarios que pueden facilitar el viaje al destino como hoteles, servicios de restauración o zonas para ir de compras. Por último, identifican elementos adicionales como el grado de accesibilidad, el transporte y aparcamiento en la ciudad junto con la oferta de información turística disponible. Y como ya se comentó, existe una relación significativa entre la imagen que los turistas tienen de un destino y su intención de visitarlo. Factores y motivaciones todos ellos que deben considerarse por parte de los líderes y por los propios turistas a la hora de valorar si la oferta de la ciudad que acoge el evento junto con la imagen que tienen los futuros turistas del destino será suficientemente significativa que se traslade en intención de visitar la ciudad. En el próximo apartado se abordará el origen del interés de Utrecht junto las razones esgrimidas por los líderes locales para organizar el GDTF 2015.

\section{EL GRAND DEPART TOUR DE FRANCIA 2015 EN UTRECHT}

Localizada en el centro de los Países Bajos y cerca del aeropuerto de Ámsterdam Schiphol, Utrecht es la cuarta ciudad más poblada del país con más de 334.000 personas (2015). En la línea de lo que argumentan Harvey (1998) y Zukin et al., (1998), Utrecht ha sido capaz de transformarse en una ciudad de consumo y, para ello, dispone de una amplia oferta de servicios universitarios (para dar respuesta a 70.000 estudiantes), culturales (que incluye, entre otros, veinticuatro museos y doce teatros), deportivos (entre los que destacan todo tipo de instalaciones, infraestructuras y servicios complementarios para la práctica del ciclismo) y edificios históricos (destaca sobremanera la catedral gótica, el Dom, y que alberga una torre de 112 metros de altura), que atraen no sólo a un número importante de personas que viven y trabajan en la ciudad, sino a un número elevado de turistas. De los casi 4 millones de personas que visitaron la ciudad en el año 2014, $540.000(13,5 \%)$ eran extranjeros, lo que la convierte en un destino consolidado. Las cifras oficiales señalan que ese mismo año 406.000 personas visitaron el Museo del Ferrocarril, 148.000 personas acudieron al Festival de Cine o 162.488 personas participaron en los domingos culturales. Y no podemos obviar una amplia extensión de canales fluviales, que ha permitido a Utrecht ser conocida como la 'Venecia del Norte'.

En un país donde el ciclismo es uno de los deportes más populares con más de 240.000 ciudadanos que utilizan con frecuencia los más de $35.000 \mathrm{kms}$ de carriles bici que ofrece el país (Statistics Netherlands, 2015), el uso que los ciudadanos locales hacen de la bicicleta y sus infraestructuras constituyen algunos de sus grandes atractivos. Para dicho uso, la ciudad dispone de $245 \mathrm{kms}$ de carriles bici que son utilizados diariamente por casi un tercio de su población (más de 100.000), bien para desplazarse al trabajo, o bien, para sus actividades 
de ocio. Al igual que sucedió con el caso del GDTF 2007 en Londres donde el evento buscaba incentivar la utilización masiva de la bicicleta (Berridge, 2012; Lovell, 2008; Smith, 2008), las autoridades han desarrollado un plan quinquenal denominado 'Utrecht. We all cycle Action Plan 2015-2020'. Con el fin de incrementar el uso interno de la bicicleta a la vez que sirva para atraer a un mayor número de turistas, este plan incluye la construcción de uno de los mayores aparcamientos de bicicletas a escala mundial en la Estación Central de Ferrocarril, con una capacidad para 12.500 bicicletas y la mejora de cinco de los carriles bici existentes. Todo ello se ve complementado con la construcción de siete nuevos carriles bici para atender a la creciente demanda ciudadana prevista para los próximos años (Ayuntamiento de Utrecht, 2015). La apuesta decidida de las autoridades locales para acrecentar el ya de por sí elevado uso de la bicicleta en la ciudad de forma accesible y segura se refuerza con la organización del GDTF 2015 que probablemente contribuya, en última instancia, en el fortalecimiento de la ciudad como destino turístico deportivo a la vez que la proyecte como referente mundial en el uso de la bicicleta. Y finalmente como nos sugiere Smith (2008) con el caso de Londres GDTF 2007, se observa una gran complementariedad entre la imagen que intenta proyectar Utrecht y la imagen y marca que representa el Tour de Francia.

\section{MÉTODO}

Tal como postulan diferentes autores (Kitzinger, 1994; Fox et al., 2014; Llopis Goig, 2004; Morgan, 1997), en este estudio exploratorio se consideró pertinente la utilización conjunta y complementaria de una técnica cuantitativa como es el caso de los cuestionarios con una técnica marcadamente cualitativa como es el grupo de discusión. Ambas técnicas nos permitían alcanzar los objetivos planteados en el estudio.

\subsection{Participantes. Procedimiento y Diseño}

Como ya se comentó en la introducción, en el diseño inicial se elaboraron originariamente dos tipos de cuestionarios (A y B) con un total de veinte preguntas formuladas en inglés, propuestos por el investigador principal del estudio y posteriormente revisados por el resto de investigadores integrantes en el estudio. Ambos cuestionarios fueron traducidos al español para analizar el caso de España. Los dos cuestionarios se estructuraban, con pequeñas diferencias, en dos partes diferenciadas. El objetivo de la primera parte se focalizaba en conocer el perfil socio-demográfico de los participantes en el estudio en España y su grado de conocimiento y experiencia previa de la ciudad de Utrecht ( 7 preguntas). Tras leer un pequeño folleto informativo sobre la ciudad, la segunda incluía un total de 13 preguntas en las que se les preguntaba sobre su valoración posterior de Utrecht (6 preguntas) y, su percepción del Tour de Francia (7 preguntas), basándose en una escala de Likert. El cuestionario A incluía un folleto con información sobre Utrecht y a modo de elemento diferenciador, se añadió una hoja con información sobre la celebración del GDTF 2015. Igualmente, el cuestionario B incorporaba información muy parecida al cuestionario A, pero en lugar de anexar información sobre el Tour, éste recogía los factores clave, en la línea de lo que postulan Law (2002) y Robinson y Gammon (2004), de Utrecht como producto turístico facilitados por la oficina de turismo local. 
El objetivo inicial de los cuestionarios era disponer de una muestra equitativa entre participantes que completasen ambos cuestionarios, atendiendo a factores como el sexo, diversidad, edad (mayores de 18 años) y localización. El trabajo de campo que se presenta se realizó con anterioridad al inicio del GDTF en julio de 2015 y se desarrolló durante el período enero a marzo de ese mismo año. Respecto a los lugares de recogida de las muestras, éstas se realizaron por medio de entrevistas de forma presencial en ciudades como Madrid, Sevilla, Cádiz, Córdoba y Tenerife. Uno de los criterios previos considerados en la recogida de datos fue que la muestra fuera lo más representativa posible, buscándose intencionalmente participantes en el estudio pertenecientes a múltiples zonas geográficas dentro del ámbito nacional. Esta dispersión geográfica nos garantiza una alta representatividad de la muestra. Otro de los criterios considerados para la selección de la muestra fue que no fuesen estudiantes universitarios. Debido a la complejidad del estudio, no se pudo realizar una selección aleatoria de los participantes, obteniéndose los datos por accesibilidad muestral. Si bien no se utilizaron técnicas estadísticas previas para la determinación del número de la muestra mínimo, se tomó la decisión estadística de, al menos, administrar ambos cuestionarios a un total de 200 sujetos de cada tipo de cuestionario (A y B). No obstante, y con el fin de evitar posibles problemas con cuestionarios incompletos o sesgados, la muestra final que compone el estudio fue de 488 sujetos. En la tabla 3 se expone la ficha técnica de la investigación del GDTF 2015 en Utrecht a tenor de cómo percibieron el evento los ciudadanos.

\section{Tabla 3}

\section{FICHA TÉCNICA DE LA INVESTIGACIÓN DEL GDTF 2015 EN ESPAÑA (ENERO-ABRIL 2015)}

\begin{tabular}{ll}
\hline Tamaño muestral & Cuestionarios: 488 \\
\hline Error muestral & $5 \%$ \\
\hline Dispersión & $\mathrm{P}=\mathrm{Q}=0,5$ \\
\hline Nivel de confianza & $95 \%$ \\
\hline Método de muestreo & Muestreo Aleatorio Simple \\
\hline Puntos de Muestreo & Madrid, Sevilla, Cádiz, Córdoba y Tenerife \\
\hline Métodos de Investigación & Cuestionarios y Grupo de Discusión \\
\hline Período de Investigación & Enero-Abril 2015 \\
\hline
\end{tabular}

Fuente: elaboración propia.

Posteriormente a la administración de los cuestionarios, se realizó un grupo de discusión con el propósito de cumplir los objetivos del estudio desde una perspectiva multimétodo (enfoque mixto mediante un análisis cuantitativo y cualitativo). Este grupo de discusión tuvo lugar en una universidad pública de Madrid el 16 de abril de 2015. Dicho grupo de discusión que incluía 6 participantes, fue moderado por el investigador principal del estudio en España. La mayoría de los participantes (5) en el grupo de discusión provenían de diferentes ciudades de España, mientras que uno era inglés, con edades comprendidas entre 30 y 50 años. Con el ánimo de fomentar el debate y el intercambio 
de opiniones sobre el objeto de estudio, el grupo de discusión era ciertamente heterogéneo e incluía a personas con diferente grado de conocimiento e interés en la organización de eventos deportivos en general y de eventos ciclistas en particular. De igual manera, dos de los participantes tenían una dilatada experiencia en el sector del turismo de eventos deportivos al trabajar en dos empresas que gestionan grandes eventos deportivos, entre los que destacan pruebas ciclistas, mientras el resto agrupaba a personas con un conocimiento medio de la gestión de pruebas ciclistas. Teniendo en cuenta uno de los objetivos del proyecto, es importante destacar que la mitad de los participantes habían estado con anterioridad en York donde se celebró el GDTF 2014, pero ninguno, por el contrario, había visitado Utrecht. La sesión tuvo una duración de una hora y diez minutos.

Al inicio de la sesión, el moderador explicó a los participantes el objetivo central del estudio y la metodología utilizada en la cual todos los participantes estaban invitados a exponer sus opiniones sobre el objeto de estudio así como intercambiar dichas opiniones con el resto. Como parte del protocolo se informó a todos los participantes que sus intervenciones iban a ser grabadas en audio con objeto de disponer de un registro magnetofónico de la sesión que permitiese su transcripción posterior tanto en español como en inglés. Tras mostrar su acuerdo, se les invitó a realizar una breve presentación de cada uno de ellos. Tras esta fase inicial, se preguntó a cada uno de ellos su opinión, grado de conocimiento y seguimiento de eventos como el Tour de Francia. A continuación, los participantes visionaron dos vídeos de corta duración sobre el GDTF 2014 en York y un vídeo promocional sobre Utrecht donde se les pidió que identificaran las principales fortalezas y debilidades de la estrategia realizada por Utrecht para promocionar su imagen a través del GDTF 2015.

\subsection{Análisis de datos}

Los datos obtenidos del proceso de recogida de datos de los cuestionarios, el análisis, su filtrado y codificación de las respuestas, se ha realizado a través del programa estadístico SPSS (Statistical Package for the Social Sciences) en su versión 20. El análisis incluye: a) análisis de frecuencias y porcentajes para los datos de carácter nominal y ordinal y b) análisis de tendencia central (medias) y de dispersión (desviaciones típicas) para las variables de carácter cuantitativo. Con el objetivo de establecer diferencias entre ambos cuestionarios, a partir de la pregunta $\mathrm{n}^{\circ} 9$ se realizaron: a) tablas de contingencia y prueba de chi-cuadrado $\left(\chi^{2}\right)$ para datos nominales y b) análisis de diferencia de medias para dos muestras independientes mediante el estadístico t de student. En el caso del grupo de discusión, y en la línea de lo que sugiere Llopis Goig (2004), se analizaron las respuestas dadas por los participantes a las preguntas clave planteadas por el moderador con el fin de identificar aquellas opiniones que se repetían y que eran comunes entre los participantes así como aquellas opiniones e ideas recurrentes, en ocasiones, expresadas de forma diversa.

\subsection{Principales Resultados del Estudio}

La primera parte de la encuesta abordaba el perfil sociodemográfico de las personas encuestadas en diferentes localidades de España. De los datos estadísticos, se observa que 
las respuestas de las mujeres representan más de la mitad $(54,1 \%)$ con respecto a las de los hombres $(45,9 \%)$. De esas cifras, se constata que la edad media de los participantes era de 41 años $(\overline{\mathrm{X}}=41,05)$. En referencia al nivel de estudios, el participante medio tenía un nivel medio-alto, predominando aquellos con estudios universitarios (45,3\%), seguidos por aquellos que tenían estudios de tipo medio (28,3\%). En el otro extremo, sólo el 9,4\% declararon tener un nivel bajo de formación. En cuanto al lugar de residencia en España, una gran parte de los encuestados residen en Cádiz (42,8\%), seguidos por Madrid $(30,1 \%)$, Córdoba $(17,2 \%)$ y Tenerife $(7,2 \%)$.

Otro dato fundamental del estudio se centraba en conocer el número de personas que había visitado con anterioridad los Países Bajos. En este sentido, los datos señalan que sólo un tercio de la muestra $(30,5 \%)$ manifestó que lo había visitado. De esta cifra, y tras preguntarles por la frecuencia de la visita, se puede inferir que ésta seguía siendo pequeña si consideramos que el $67 \%$ había estado sólo una vez, mientras que sólo el 18,1\% lo había visitado en dos ocasiones. Al serles preguntado por su valoración, todos manifestaron que su experiencia había sido muy positiva (8,20 de media sobre 10$)$. De las personas que habían visitado el país, lo más destacado fue el escaso número de personas $(7,2 \%)$ que habían visitado a su vez Utrecht, a pesar de su cercanía del aeropuerto de Ámsterdam Schiphol. Por ello, a priori, el grado de conocimiento de los atractivos turísticos, culturales y deportivos que ofrece Utrecht es limitado. Mientras tanto, debemos destacar que aquellos que habían visitado la ciudad le otorgaron una nota elevada (8,14 de media) a su experiencia.

Otro aspecto relevante incidía en identificar aquellos factores clave más valorados por los futuros turistas de España y que mejor describen a Utrecht como producto turístico; aspecto que, como se argumenta en la literatura, puede condicionar la intención de la visita. Aquellos encuestados que habían estado en la ciudad optaron por definir a la ciudad con palabras como: histórica/historia (19\%), culta, cultural/cultura (13,5\%), dinámica $(5,3 \%)$, interesante $(4,9 \%)$, moderna $(4,7 \%)$ y bonita $(4,1 \%)$, mientras que aquellos que no habían estado utilizaron términos como culta, cultural y cultura $(15,8 \%)$; histórica/historia $(10,1 \%)$; dinámica $(6,8 \%)$, moderna $(6,5 \%)$, interesante $(4,5 \%)$ y cosmopolita $(4,3 \%)$. Asimismo, al ser preguntados por la probabilidad de viajar a Utrecht en el futuro (en una escala Likert de 1 a 10 puntos), un alto porcentaje $(5,09)$ consideraba dicha posibilidad. La cifra aumentaba al 6,19 cuando se les preguntaba si recomendarían la visita a otras personas.

Llegados al evento en sí mismo, y al ser preguntados por su valoración, por su grado de seguimiento, y por los medios de comunicación utilizados para dicho seguimiento así como por su valoración global del evento, podemos destacar que sólo el 26,9\% seguía con frecuencia esta prueba. La cifra expuesta es coincidente, en gran medida, con la Encuesta de Hábitos Deportivos 2015 (MECD, 2015b) que destaca que el 30,8\% de los españoles se declaran seguidores del ciclismo a través de los medios audiovisuales. La encuesta refleja, por el contrario, que casi un tercio $(28,8 \%)$ no lo seguía nunca, mientras que un $44,3 \%$ de los encuestados manifestó que en ocasiones seguía la vuelta ciclista. De los que eran asiduos seguidores del evento, el tiempo que dedicaban a su seguimiento era limitado, si consideramos que más de la mitad $(55,3 \%)$ sólo lo seguía no más de 15 minutos, seguidos por un $36,3 \%$ que dedicaba atención al evento entre 15 y 60 minutos. De esta cifra, solo el 27,6\% 
utilizaba diferentes medios audiovisuales (periódicos, televisión, internet..) para seguir la prueba. En general, y en una escala de 1 a 7 puntos, un alto porcentaje $(4,28)$ consideraba al Tour como un evento excitante para ver, resaltándole como uno de los grandes eventos deportivos a nivel mundial $(5,36)$, y por el contrario, su valoración como un evento aburrido para ver (3,31 de media) y un número elevado considera que el Tour es seguido solo por ciudadanos europeos $(4,05)$. De la misma forma, varios de los participantes valoraron de forma diversa la relevancia del Tour de Francia y su grado de seguimiento.

'El impacto de la organización de una etapa del Tour es muy importante no sólo para el organizador, sino también para la ciudad que lo acoge o que lo recibe puesto que los ciclistas suelen pasar entre dos y tres noches como viene sucediendo en la mayoría de las vueltas ciclistas que he estado siguiendo (Participante 2).

Ante la posibilidad de poder seguir una etapa del Tour si hubiera una oportunidad, aspecto éste que entronca claramente con su disposición a viajar a Utrecht para seguir in situ el evento, como establecen Weed y Bull (2004) y Weed (2008, 2009). En una escala de 1 a 7 puntos, los resultados resaltan un interés notable por el evento (4,02 de media), pero que disminuye $(3,91)$ cuando se les preguntaba si estarían dispuestos a hacer una parada para seguir una etapa del Tour dentro de su plan de viaje (como propugna el turismo de eventos deportivos) y disminuye aún más si no dudarían en reservar un viaje para asistir a una etapa del Tour $(3,13)$. En esta misma línea, los encuestados mostraron un bajo nivel de interés (entendidos como personas indiferentes a que el evento tenga lugar o no, por lo que éste apenas tiene influencia en su plan de viaje) en viajar para seguir un evento del prestigio del Tour de Francia si observamos que solo (media 3,15 ) en una escala de 1 a 10 puntos estarían dispuestos a viajar para seguir una etapa del Tour en el futuro o que recomendasen dicho viaje a familiares y amigos (3,94 de media). Este es un elemento negativo destacado si tenemos en cuenta que los turistas fieles suelen recomendar el destino a diferentes grupos. En una escala de 1 a 10, una media de 5,77 puntos manifestó que realiza actividad deportiva con frecuencia, mientras que su valoración como aficionados deportivos se situó en 5,73 puntos.

Respecto a las once cuestiones que componen la pregunta $\mathrm{n}^{\circ} 9$, podemos observar cómo los participantes del cuestionario A otorgaron una puntuación mayor de 5 puntos en siete preguntas (un $63,64 \%$ ), mientras que en el cuestionario B fue de ocho $(72,73 \%$ ). En ambos subgrupos, los participantes otorgaron las menores puntuaciones $(<5$ puntos) a las cuestiones "9.11.Considero que Utrecht es una ciudad con buen clima" y "9.10.Considero que Utrecht es una ciudad asequible económicamente" (puntuaciones < 4.34). De forma descriptiva, el cuestionario B obtiene mayores puntuaciones en todas las 11 cuestiones de la pregunta 9. De forma más precisa, la realización de los análisis de diferencia de medias mediante el estadístico t de student muestra diferencias estadísticamente significativas en las preguntas 9.7 y 9.10 (ambas con una $p<.05$ ), hallando mayores puntuaciones en el cuestionario B. A pesar de no encontrarse diferencias estadísticamente significativas, se observan resultados con tendencia a la significación estadística $(p<.10)$ en las preguntas $9.2,9.3,9.8$ y 9.11, encontrándose de nuevo mayores puntuaciones en el cuestionario B como se aprecia en las siguientes tablas. 
Tabla 4

ANÁLISIS DESCRIPTIVOS Y DE DIFERENCIA DE MEDIAS EN LA PREGUNTA No9 (CUESTIONARIO A, N=232; CUESTIONARIO B, N=256)

\begin{tabular}{|c|c|c|c|c|c|}
\hline & $\begin{array}{c}\text { Modelo de } \\
\text { Cuestionario }\end{array}$ & $M$ & $S D$ & $\mathrm{t}$ & Sig. \\
\hline \multirow{2}{*}{$\begin{array}{l}\text { 9.1. Considero que Utrecht es una ciudad con } \\
\text { una historia interesante }\end{array}$} & Cuestionario A & 5,51 & 1,147 & -.102 & .919 \\
\hline & Cuestionario B & 5,52 & 1,130 & & \\
\hline \multirow{2}{*}{$\begin{array}{l}\text { 9.2. Considero que Utrecht es una ciudad con } \\
\text { un paisaje atractivo }\end{array}$} & Cuestionario A & 5,38 & 1,090 & $-1,723$ & $.086 \dagger$ \\
\hline & Cuestionario B & 5,55 & 1,105 & & \\
\hline \multirow{2}{*}{$\begin{array}{l}\text { 9.3. Considero que Utrecht es una ciudad } \\
\text { con un estilo de vida y costumbres } \\
\text { interesantes }\end{array}$} & Cuestionario A & 5,13 & 1,060 & -1.831 & $.068 \dagger$ \\
\hline & Cuestionario B & 5,30 & 1,059 & & \\
\hline \multirow{2}{*}{$\begin{array}{l}\text { 9.4. Considero que Utrecht es una ciudad con } \\
\text { esplendor internacional }\end{array}$} & Cuestionario A & 4,88 & 1,278 & -1.024 & .307 \\
\hline & Cuestionario B & 4,99 & 1,166 & & \\
\hline \multirow{2}{*}{$\begin{array}{l}\text { 9.5. Considero que Utrecht es una ciudad con } \\
\text { interesantes actividades culturales }\end{array}$} & Cuestionario A & 5,56 & 961 & -.112 & .911 \\
\hline & Cuestionario B & 5,57 & 1,068 & & \\
\hline \multirow{2}{*}{$\begin{array}{l}\text { 9.6. Considero que Utrecht es una ciudad con } \\
\text { grandes eventos }\end{array}$} & Cuestionario A & 5,28 & 1,106 &,- 088 & .930 \\
\hline & Cuestionario B & 5,29 & 1,128 & & \\
\hline \multirow{2}{*}{$\begin{array}{l}\text { 9.7. Considero que Utrecht es una ciudad con } \\
\text { una infraestructura muy desarrollada }\end{array}$} & Cuestionario A & 5,10 & 1,106 & -2.509 & $.012 *$ \\
\hline & Cuestionario B & 5,36 & 1,146 & & \\
\hline \multirow{2}{*}{$\begin{array}{l}\text { 9.8. Considero que Utrecht es una ciudad con } \\
\text { una vida nocturna atractiva }\end{array}$} & Cuestionario A & 4,91 & 1,083 & -1.906 & $.057 \dagger$ \\
\hline & Cuestionario B & 5,10 & 1,136 & & \\
\hline \multirow{2}{*}{$\begin{array}{l}\text { 9.9. Considero que Utrecht es una ciudad con } \\
\text { múltiples actividades }\end{array}$} & Cuestionario A & 5,32 & 1,102 & -1.481 & .139 \\
\hline & Cuestionario B & 5,46 & 1,073 & & \\
\hline \multirow{2}{*}{$\begin{array}{l}\text { 9.10. Considero que Utrecht es una ciudad } \\
\text { asequible económicamente }\end{array}$} & Cuestionario A & 4,08 & 1,116 & -2.360 & $.019 *$ \\
\hline & Cuestionario B & 4,33 & 1,216 & & \\
\hline \multirow{2}{*}{$\begin{array}{l}\text { 9.11. Considero que Utrecht es una ciudad } \\
\text { con un buen clima }\end{array}$} & Cuestionario A & 3,73 & 1,206 & -1.823 & $.069+$ \\
\hline & Cuestionario B & 3,95 & 1,402 & & \\
\hline
\end{tabular}

$\dagger p<.10 ; * p<.05$

Respecto a la pregunta $\mathrm{n}^{\circ} 10$, se observa una mayor homogenidad en las puntuaciones obtenidas que en la pregunta $\mathrm{n}^{\circ} 9$ (todas ellas entre 4,52 y 5,40). Excepto en las preguntas 10.8 y 10.9, en el cuestionario B se obtienen mayores puntuaciones. Los análisis de diferencia de medias muestran diferencias estadísticamente significativas en las preguntas 10.14 y 10.14 (ambas con $p<.05$ ). Igualmente, se observan resultados con una tendencia a la significación estadística $(p<.10)$ en las cuestiones $10.1,10.4,10.5$ y 10.13 . 
Tabla 5

ANÁLISIS DESCRIPTIVOS Y DE DIFERENCIA DE MEDIAS EN LA PREGUNTA No10 (CUESTIONARIO A , N=232; CUESTIONARIO B, N=256)

\begin{tabular}{|c|c|c|c|c|c|}
\hline & $\begin{array}{c}\text { Modelo de } \\
\text { Cuestionario }\end{array}$ & $M$ & $S D$ & $\mathrm{t}$ & Sig. \\
\hline \multirow{2}{*}{$\begin{array}{l}\text { 10.1. Considero que Utrecht es una ciudad } \\
\text { lujosa }\end{array}$} & Cuestionario A & & 1,114 & $-1,832$ & $.068 \dagger$ \\
\hline & Cuestionario B & 4,61 & 1,161 & & \\
\hline \multirow{2}{*}{$\begin{array}{l}\text { 10.2. Considero que Utrecht es una ciudad } \\
\text { con energía }\end{array}$} & Cuestionario A & 5,13 & 1,063 &,- 598 &, 550 \\
\hline & Cuestionario B & 5,19 & 1,069 & & \\
\hline \multirow{2}{*}{$\begin{array}{l}\text { 10.3. Considero que Utrecht es una ciudad } \\
\text { cosmopolita }\end{array}$} & Cuestionario A & 5,35 & 1,149 &,- 862 & .389 \\
\hline & Cuestionario B & 5,44 & 1,115 & & \\
\hline \multirow{2}{*}{$\begin{array}{l}\text { 10.4. Considero que Utrecht es una ciudad } \\
\text { limpia }\end{array}$} & Cuestionario A & 5,21 & 1,137 & $-1,883$ & $.060 \dagger$ \\
\hline & Cuestionario B & 5,41 & 1,191 & & \\
\hline \multirow{2}{*}{$\begin{array}{l}\text { 10.5. Considero que Utrecht es una ciudad } \\
\text { segura }\end{array}$} & Cuestionario A & 5 , & 1,149 & $-1,809$ & $.071 \dagger$ \\
\hline & Cuestionari & & 1,132 & & \\
\hline \multirow{2}{*}{$\begin{array}{l}\text { 10.6. Considero que Utrecht es una ciudad } \\
\text { acogedora }\end{array}$} & Cuestionari & 5,28 & 1,083 & -1.090 & .276 \\
\hline & Cuestionario B & 5,39 & 1,149 & & \\
\hline \multirow{2}{*}{$\begin{array}{l}\text { 10.7. Considero que Utrecht es una ciudad } \\
\text { de moda }\end{array}$} & Cuestionario A & 4,91 & 1,197 & -.466 & .641 \\
\hline & Cues & & 1,236 & & \\
\hline \multirow{2}{*}{$\begin{array}{l}\text { 10.8 Considero que Utrecht es una ciudad } \\
\text { joven }\end{array}$} & Cuestionario A & 5,30 & 1,229 & .527 & .599 \\
\hline & Cuestionario B & & 1,263 & & \\
\hline \multirow{2}{*}{$\begin{array}{l}\text { 10.9. Considero que Utrecht es una ciudad } \\
\text { pequeña }\end{array}$} & Cuestionario A & 5,09 & 1,166 & .227 & .831 \\
\hline & Cuestionario B & 5,07 & 1,215 & & \\
\hline \multirow{2}{*}{$\begin{array}{l}\text { 10.10. Considero que Utrecht es una ciudad } \\
\text { dinámica }\end{array}$} & Cuestionario A & 5,35 & 1,122 & -.208 & .835 \\
\hline & Cuestionaric & 5 , & 1,198 & & \\
\hline \multirow{2}{*}{$\begin{array}{l}\text { 10.11. Considero que Utrecht es una ciudad } \\
\text { de clase alta }\end{array}$} & Cuestionario A & 4,71 & 1,108 & -1.379 & .168 \\
\hline & Cuestionario B & 4,85 & 1,076 & & \\
\hline \multirow{2}{*}{$\begin{array}{l}\text { 10.12. Considero que Utrecht es una ciudad } \\
\text { emocionante }\end{array}$} & Cuestionario A & 4,84 & 1,048 & -1.584 & .114 \\
\hline & Cuestionario B & 4,99 & 1,120 & & \\
\hline \multirow{2}{*}{$\begin{array}{l}\text { 10.13. Considero que Utrecht es una ciudad } \\
\text { contemporánea }\end{array}$} & Cuestionario A & 5,07 & 1,156 & -1.743 & $.082 \dagger$ \\
\hline & Cuestionario B & 5,25 & 1,147 & & \\
\hline \multirow{2}{*}{$\begin{array}{l}\text { 10.14. Considero que Utrecht es una ciudad } \\
\text { inspiradora }\end{array}$} & Cuestionario A & 4,90 & 1,096 & -2.326 & $.020 *$ \\
\hline & Cuestionario B & 5,13 & 1,107 & & \\
\hline \multirow{2}{*}{$\begin{array}{l}\text { 10.15. Considero que Utrecht es una ciudad } \\
\text { guay }\end{array}$} & Cuestionario A & 4,84 & 1,299 & -2.479 & \multirow[b]{2}{*}{$.014 *$} \\
\hline & Cuestionario B & 5,12 & 1,239 & & \\
\hline
\end{tabular}

$\dagger p<.10 ;{ }^{*} p<.05$ 


\section{Tabla 6}

ANÁLISIS DESCRIPTIVOS Y DE DIFERENCIA DE MEDIAS EN LA PREGUNTA N9 (CUESTIONARIO A , N=232; CUESTIONARIO B, N=256)

\begin{tabular}{llllll}
\hline & $\begin{array}{c}\text { Modelo de } \\
\text { Cuestionario }\end{array}$ & $M$ & $S D$ & t & Sig. \\
\hline $\begin{array}{l}\text { 11.1. Si tuviese la oportunidad, me } \\
\text { gustaría visitar Utrecht }\end{array}$ & $\begin{array}{c}\text { Cuestionario A } \\
\text { Cuestionario B }\end{array}$ & 5,62 & 1,253 & -2.026 & $.043^{*}$ \\
$\begin{array}{l}\text { 11.2. Si tuviese la oportunidad, me } \\
\text { gustaría visitar Utrecht formando }\end{array}$ & Cuestionario A & 5,92 & 1,137 & & \\
$\begin{array}{l}\text { parte de un viaje a los Países Bajos } \\
\begin{array}{l}\text { 11.3. Si tuviese la oportunidad, no } \\
\text { dudaría en realizar una reserva para }\end{array}\end{array}$ & Cuestionario B & 5,96 & 1,293 & -3.13 & .755 \\
$\begin{array}{l}\text { visitar Utrecht } \\
\text { Cuestionario A }\end{array}$ & 4,97 & 1,551 & & \\
\hline
\end{tabular}

$* p<.05 ; * * p<.01$

Respecto a la pregunta $\mathrm{n}^{\circ} 11$, se observan puntuaciones ligeramente más elevadas que en las dos cuestiones anteriores, siendo el rango de puntuaciones medias halladas más elevadas que en la pregunta $\mathrm{n}^{\circ} 10$. En todos los casos se observan mayores puntuaciones en el cuestionario $\mathrm{B}$, en donde los análisis de diferencias muestran las mayores diferencias en la pregunta $11.3(p<.01)$, seguidas de las diferencias halladas en la pregunta 11.1 $(p<.05)$. Centrándonos en las preguntas 12 y 13, en el cuestionario B se observan las mayores puntuaciones. Son especialmente relevantes las elevadas puntuaciones obtenidas en la pregunta $\mathrm{n}^{\mathrm{0}} 3$, y especialmente en el cuestionario B. Los análisis de diferencia de medias muestran importantes diferencias estadísticamente significativas en la pregunta $\mathrm{n}^{\mathrm{o}} 13(p<.01)$.

\section{Tabla 7}

ANÁLISIS DESCRIPTIVO Y DE DIFERENCIA DE MEDIAS EN LA PREGUNTA No12 (CUESTIONARIO A , N=232; CUESTIONARIO B, N=256)

\begin{tabular}{|c|c|c|c|c|c|}
\hline & $\begin{array}{c}\text { Modelo de } \\
\text { Cuestionario }\end{array}$ & $M$ & $S D$ & $\mathrm{t}$ & Sig. \\
\hline \multirow{2}{*}{$\begin{array}{l}\text { 12. En una escala de } 1 \text { a } 10 \text { ( } 1 \text { Improbable, } \\
10 \text { Muy Probable), indique qué } \\
\text { probabilidad existe de que Ud. viaje a } \\
\text { Utrecht en el futuro. }\end{array}$} & Cuestionario A & 4,94 & 2,309 & \multirow[b]{2}{*}{-1.370} & \multirow[b]{2}{*}{.171} \\
\hline & Cuestionario B & 5,23 & 2,373 & & \\
\hline \multirow{2}{*}{$\begin{array}{l}\text { 13. En una escala de } 1 \text { a } 10 \text {, indiqué si } \\
\text { recomendaría visitar Utrecht a otras } \\
\text { personas. }\end{array}$} & Cuestionario A & 5,90 & 2,129 & \multirow[b]{2}{*}{-2.627} & \multirow[b]{2}{*}{$.009 * *$} \\
\hline & Cuestionario B & 6,45 & 2,512 & & \\
\hline
\end{tabular}

$* * p<.01$ 
Considerando la pregunta $\mathrm{n}^{\circ} 14$, se realizaron los correspondientes análisis de frecuencias mediante la prueba de contingencia para las preguntas 14.1, 14.2 y 14.3. Aplicando la prueba Chi-cuadrado $\left(\chi^{2}\right)$, no se obtienen diferencias significativas en las frecuencias de respuesta en función de los dos cuestionarios entregados $\left(14.1, \chi^{2=} .940, p=.816 ; 14.2\right.$., $\left.\chi^{2=} .353, p=.838 ; 14.3, \chi^{2=1}, 190, p=.575\right)$.

Tabla 8

ANÁLISIS DESCRIPTIVO DE LA PREGUNTA Nº14.1

\begin{tabular}{llccccc}
\hline & & Nunca & $\begin{array}{c}\text { Algunas } \\
\text { veces }\end{array}$ & $\begin{array}{c}\text { A } \\
\text { menudo }\end{array}$ & $\begin{array}{c}\text { A } \\
\text { diario }\end{array}$ & Total \\
\hline 14.1. Durante su celebración, & Cuestionario A & 69 & 103 & 40 & 20 & 232 \\
indique la frecuencia con la que & Cuestionario B & 72 & 113 & 52 & 19 & 256 \\
ve el Tour de Francia & Total & 141 & 216 & 92 & 39 & 488 \\
& & & & & & \\
\hline
\end{tabular}

Tabla 9

ANÁLISIS DESCRIPTIVO DE LA PREGUNTA Nº14.2

\begin{tabular}{lcccccc}
\hline & & $\begin{array}{c}\text { Menos } \\
\text { de 15 } \\
\text { minutos }\end{array}$ & $\begin{array}{c}\text { Entre 15 y } \\
60 \text { minutos }\end{array}$ & $\begin{array}{c}\text { Más de 60 } \\
\text { minutos }\end{array}$ & Total \\
\hline 14.2. Cuando sigue el Tour, & Cuestionario A & 131 & 81 & 20 & 232 \\
indique la cantidad de tiempo & Cuestionario B & 139 & 98 & 21 & 256 \\
& Total & 270 & 177 & 41 & 488 \\
\hline
\end{tabular}

Tabla 10

ANÁLISIS DESCRIPTIVO DE LA PREGUNTA Nº14.3

\begin{tabular}{lcccccc}
\hline & & Nunca & $\begin{array}{c}\text { Algunas } \\
\text { veces }\end{array}$ & $\begin{array}{c}\text { A } \\
\text { menudo }\end{array}$ & $\begin{array}{c}\text { A } \\
\text { diario }\end{array}$ & Total \\
\hline 14.3. Indique la frecuencia & Cuestionario A & 72 & 95 & 39 & 26 & 232 \\
con la qué sigue el Tour en & Cuestionario B & 80 & 106 & 50 & 20 & 256 \\
los medios de comunicación & Total & 152 & 201 & 89 & 46 & 488 \\
(periódicos, internet ..etc) & & & & &
\end{tabular}

Respecto a la pregunta $\mathrm{n}^{\mathrm{0}} 15$, y a diferencia de las anteriores preguntas, se puede observar como las puntuaciones medias obtenidas considerando los cuestionarios A y el B, son prácticamente las mismas. De forma descriptiva, a excepción de la pregunta 15.5, el cuestionario A obtiene unas puntuaciones algo más elevadas que el cuestionario B. Sin embargo, los análisis de diferencia de medias muestran la ausencia de diferencias estadísticamente significativas. 
Tabla 11

ANÁLISIS DESCRIPTIVO Y DE DIFERENCIA DE MEDIAS DE LAS PREGUNTAS Nº15.1, $\mathrm{N}^{0} 15.2, \mathrm{~N}^{\circ} 15.3, \mathrm{~N}^{\circ} 15.4, \mathrm{Y} \mathrm{N}^{\circ} 15.5$

\begin{tabular}{|c|c|c|c|c|c|}
\hline & $\begin{array}{c}\text { Modelo de } \\
\text { Cuestionario }\end{array}$ & $M$ & $S D$ & $\mathrm{t}$ & Sig. \\
\hline \multirow{2}{*}{$\begin{array}{l}\text { 15.1. En general, considera que el Tour de } \\
\text { Francia es un evento excitante para ver. }\end{array}$} & Cuestionario A & 4,30 & 1,801 & \multirow[t]{2}{*}{2,66} & \multirow[t]{2}{*}{.790} \\
\hline & Cuestionario B & 4,26 & 1,842 & & \\
\hline \multirow{2}{*}{$\begin{array}{l}\text { 15.2. En general, considera que el Tour } \\
\text { de Francia es uno de los grandes eventos } \\
\text { deportivos a nivel mundial. }\end{array}$} & Cuestionario A & 5,40 & 1,548 & \multirow[t]{2}{*}{5,14} & \multirow[t]{2}{*}{.608} \\
\hline & Cuestionario B & 5,32 & 1,557 & & \\
\hline \multirow{2}{*}{$\begin{array}{l}\text { 15.3. En general, considera que el Tour de } \\
\text { Francia es un evento aburrido para ver }\end{array}$} & Cuestionario A & 3,33 & 1,915 & \multirow[t]{2}{*}{,197 } & \multirow[t]{2}{*}{844} \\
\hline & Cuestionario B & 3,30 & 1,997 & & \\
\hline \multirow{2}{*}{$\begin{array}{l}\text { 15.4. En general, considera que el Tour de } \\
\text { Francia es uno de los mejores eventos a nivel } \\
\text { mundial }\end{array}$} & Cuestionario A & 4,66 & 1,620 & \multirow[t]{2}{*}{, 430} & \multirow[t]{2}{*}{ 668 } \\
\hline & Cuestionario B & 4,59 & 1,536 & & \\
\hline \multirow{2}{*}{$\begin{array}{l}\text { 15.5. En general, considera que el Tour de } \\
\text { Francia es visto/seguido solo por ciudadanos } \\
\text { europeos }\end{array}$} & Cuestionario A & 4,00 & 1,618 & \multirow[t]{2}{*}{,- 673} & \multirow[t]{2}{*}{, 501} \\
\hline & Cuestionario B & 4,09 & 1,596 & & \\
\hline
\end{tabular}

En la pregunta $\mathrm{n}^{\circ} 16$ se puede observar cómo, a excepción de la pregunta 16.1, el cuestionario B obtiene mayores puntuaciones que el de tipo A. Asimismo, se obtienen bajas puntuaciones en la pregunta 16.3, especialmente en el cuestionario A. Los análisis de diferencia de medias no muestran diferencias estadísticamente significativas, si bien se muestran resultados con tendencia a la significación estadística $(p<.10)$.

Tabla 12

ANÁLISIS DESCRIPTIVO Y DE DIFERENCIA DE MEDIAS DE LAS PREGUNTAS N'16.1, $\mathrm{N}^{\mathrm{o}} 16.2, \mathrm{~N}^{\mathrm{0}} 16.3$

\begin{tabular}{|c|c|c|c|c|c|}
\hline & $\begin{array}{c}\text { Modelo de } \\
\text { Cuestionario }\end{array}$ & $M$ & $S D$ & $\mathrm{t}$ & Sig. \\
\hline \multirow{2}{*}{$\begin{array}{l}\text { 16.1. Si tuviese la oportunidad, me gustaría } \\
\text { seguir una etapa del Tour de Francia }\end{array}$} & Cuestionario A & 4,05 & 2,036 & \multirow[t]{2}{*}{,277 } & \multirow[t]{2}{*}{,782 } \\
\hline & Cuestionario B & 4,00 & 2,083 & & \\
\hline \multirow{2}{*}{$\begin{array}{l}\text { 16.2. Si tuviese la oportunidad, me gustaría } \\
\text { hacer una parada para seguir una etapa del } \\
\text { Tour dentro de mi plan de viaje }\end{array}$} & Cuestionario A & 3,76 & 2,043 & \multirow[t]{2}{*}{$-1,551$} & \multirow[t]{2}{*}{, 121} \\
\hline & Cuestionario B & 4,05 & 2,051 & & \\
\hline \multirow{2}{*}{$\begin{array}{l}\text { 16.3. Si tuviese la oportunidad, no dudaría } \\
\text { en reservar un viaje para asistir a una etapa } \\
\text { del Tour }\end{array}$} & Cuestionario A & 2,94 & 2,015 & \multirow[t]{2}{*}{$-1,901$} & \multirow[t]{2}{*}{, $058 \dagger$} \\
\hline & Cuestionario B & 3,29 & 2,034 & & \\
\hline
\end{tabular}

$\dagger p<.10$ 
Considerando las preguntas 17, 18, 19 y 20, se puede observar cómo, a excepción de la pregunta 20, las puntuaciones del cuestionario B son más elevadas que las del tipo A. Se observan puntuaciones relativamente bajas en ambos cuestionarios en la pregunta 17, siendo más elevadas en las preguntas 19 y 20. Sin embargo, los análisis de diferencia de medias no muestran resultados estadísticamente significativos al comparar las puntuaciones de ambos cuestionarios.

Sobre la trascendencia de organizar el GDTF en Utrecht como estrategia de promoción internacional de la ciudad, uno de los participantes resaltaba tras ver un vídeo promocional de Utrecht que:

'Obviamente organizar el GDTF en Utrecht es una gran oportunidad para la promoción internacional de la ciudad. En mi caso, no conocía nada sobre la ciudad y debo admitir que sólo había oído algo sobre la ciudad. Este vídeo muestra una ciudad muy atractiva sobre todo en lo que concierne a la oferta de museos y de una forma muy positiva. No iría al Tour de Francia porque no soy muy aficionado al ciclismo, pero sí que ha captado imágenes positivas de la ciudad. Si alguna vez. planease ir a los Países Bajos, consideraría ir a Utrecht. Para alguien que no es aficionado al ciclismo diría que la organización del GDTF en Utrecht ofrece una gran oportunidad para incrementar la visibilidad de la ciudad y eso es importante para convencerte para visitarla. Aunque es difícil evaluar este aspecto' (participante 4).

Otro participante se mostraba escéptico ante el grado de eficacia del vídeo cuando se trataba de incrementar la visibilidad de la ciudad unida al GDTF 2015 al manifestar que:

'El vídeo de Utrecht es bueno para su promoción turística porque incluye imágenes con explicaciones de lo que vas viendo lo cual genera mayor atención. Pero si la ciudad quiere promocionarse con este vídeo, no creo que sea lo más adecuado .. A pesar de que existe una importante tradición ciclista, en el vídeo no aparece ninguna imagen de una bicicleta. Esto es un grave error. Si Utrecht quiere promocionarse yo hubiera elegido otras vías u otro tipo de vídeo...Los impactos que se espera conseguir con este vídeo son erróneos y no creo que sea el mejor evento para este tipo de promoción'.

Otro de los participantes aludía a las dificultades logísticas de organizar un evento de la dimensión del Tour en una ciudad histórica como Utrecht cuando afirmaba que: 'No creo que Utrecht sea una localidad ideal para albergar una etapa del Tour. Si la ciudad tiene canales en las zonas históricas, será imposible organizar un sprint masivo como el Tour requiere. Además, si no pueden entrar los camiones de la caravana por sus calles, la gente se perderá uno de los principales atractivos como es la caravana del Tour' (participante 2). 
La mayoría de los participantes en el grupo de discusión coinciden a la hora de señalar que el Tour de Francia es uno de los grandes eventos a nivel mundial, seguido por muchos españoles durante su celebración en julio. Sin embargo, otros incidieron en ciertos aspectos que podrían ayudar en la promoción de la imagen de la ciudad al comentar que ' $\mathrm{Si}$ los organizadores quieren atraer a la ciudad a un segmento de turistas internacionales como son los españoles, deberían haber incluido más imágenes de personas utilizando bicicletas, organización de festivales en las calles...También es clave el disponer de amplias zonas de parking en la ciudad para acoger a los camiones de los equipos y de los medios, que es uno de los grandes atractivos'.

\section{CONCLUSIONES E IMPLICACIONES PRÁCTICAS}

Los datos mostrados por organismos internacionales y nacionales ponen de manifiesto la trascendencia del turismo de eventos deportivos como un sector productivo especializado y con un gran potencial de crecimiento en numerosos países, como destaca nuestro país con un gran número de ciudades y un amplio espectro de Comunidades Autónomas (Fernández Alles, 2014). Las ciudades son un magnífico laboratorio donde examinar el potencial de los eventos deportivos como productos turísticos. Como se recoge en el presente artículo, los propios eventos deportivos pueden contribuir a la proyección turística del destino con la difusión de una nueva identidad e imagen que sirve para atraer a un segmento cada vez más relevante tanto cuantitativo como cualitativamente como el que representa el turista deportivo. Sin duda, uno de los impactos más visible es el fomento del turismo incluso después del propio evento.

El evento se configura, por tanto, como una magnífica oportunidad para ayudar en el proceso de redefinición de la ciudad o, en su caso, en el fortalecimiento de la propia imagen de la ciudad. En esta línea, el atractivo turístico de Utrecht es evidente a tenor del ingente número de turistas nacionales e internacionales que visitan anualmente la ciudad. Esta posición puede verse reforzada con la organización de uno de los grandes eventos deportivos internacionales como representa el GDTF 2015. No obstante, algunos de los participantes en el grupo de discusión manifestaron ciertas dudas sobre el grado de efectividad del evento ciclista.

A la hora de abordar el estudio de la imagen e identidad de las ciudades, Fernández Alles (2014), Law (2002) y Wicker et al, (2012) resaltan diferentes factores que pueden contribuir tanto a la proyección del destino en unos casos como a fortalecer la imagen de la ciudad, entre los que se incluyen, sin atender a un orden jerárquico, las infraestructuras que dispone la propia ciudad, los atractivos primarios, secundarios y adicionales de la propia ciudad, el carácter de ésta, la calidad de vida y los propios ciudadanos. En el caso particular de Utrecht, la ciudad dispone de una amplia oferta cultural, social y deportiva, entre la que se incluye un alto nivel de infraestructuras (deportivas y no deportivas) para la práctica cotidiana de uno de los deportes más populares en la ciudad y en el país. Del estudio se puede afirmar que un evento global como el GDTF 2015 es totalmente coherente con la identidad de la ciudad a la par que puede ayudar a aumentar la afluencia de turistas. A la vez, el evento puede ayudar a medio y a largo plazo a consolidar Utrecht 
como una 'ciudad para la bicicleta'. Pero para conseguir los objetivos mencionados, es necesario que las autoridades locales planifiquen adecuadamente la organización del evento y se preparen para atender a las necesidades logísticas y organizativas de un evento como el GDTF 2015. En la línea de lo que propugnan Álvarez del Blanco (1993); Green et al., (2008) y Kavaratzis (2004), todos los esfuerzos a la hora de promocionar la imagen de la ciudad se deben focalizar hacia el exterior, pero sin olvidar a los propios habitantes de la ciudad. Por ello, se debe planificar y comunicar adecuadamente hacia el exterior y hacia sus propios habitantes los atractivos primarios y secundarios de la ciudad. En esta labor de promoción del destino, los medios de comunicación son clave. Sin una adecuada planificación de ambos aspectos (logísticos del propio evento y la promoción de la imagen a través de diferentes medios de comunicación), la ciudad puede conseguir menos beneficios. Todo ello sin obviar que la suerte de muchos eventos también depende de factores económicos y políticos coyunturales que escapan muchas veces al control de ámbito local. Como ya se comentó el éxito socio-económico del GDTF 2015 en Utrecht viene determinado por la valoración positiva por parte de los residentes locales, pero, sobre todo, por la capacidad para generar una gran afluencia de turistas nacionales e internacionales. Este hecho puede estimular un gran gasto económico en la ciudad. Si antes del evento las previsiones más optimistas situaban entre 500.000 y 800.000 el número de visitantes, diferentes medios locales resaltan que finalmente fueron 350.000 los que asistieron a la ciudad para seguir el evento.

Ante la complejidad que conlleva planificar, organizar y evaluar los impactos asociados a un evento tal como resaltan Buldeck et al., (2011), Higham (2005) y Smith (2008), el caso específico de Utrecht sirve para ilustrar la utilidad de realizar estudios previos al evento como el que se presenta aquí para disponer de datos objetivos que permitan conocer si un evento como el GDTF 2015 tiene el potencial suficiente para posicionar a la ciudad como destino turístico y atraer a aquellos visitantes de los países considerados potenciales mercados, bien por su tradición ciclista o por ser mercados relevantes en el sector del turismo. Entendiendo el evento deportivo como un producto turístico, una de las estrategias pasaría por realizan campañas de marketing que se dirijan específicamente a los principales mercados de los países tanto con tradición ciclista como España, pero sobre todo con aquellos países con poca tradición ciclista. Si la exposición mediática del evento sirve para aumentar la imagen de una ciudad, otro de los puntos que habría que mejorar sería el vídeo promocional de la ciudad que resalte no sólo los principales atractivos, sino, sobre todo, debería incluir más referencias a la importante cultura ciclista de Utrecht. No menos importante es que aquellas ciudades que deseen promocionar y proyectar imágenes como es el caso de Utrecht deben formular un plan estratégico a medio plazo como evidencian los casos de ciudades Barcelona e Indianápolis. Como ha quedado de manifiesto en la discusión, el estudio del turismo de eventos deportivos ha alcanzado una gran notoriedad a escala global que ha conducido a atraer la atención de investigadores, fundamentalmente anglosajones, pero todavía con una escasa incidencia en la bibliografía en español especializada sobre este sector como resalta Jiménez Martín (2011). Por este motivo, esperamos que este trabajo sirva para expandir y motivar otros estudios en este campo en España. 


\section{BIBLIOGRAFÍA}

ÁLVAREZ DEL BLANCO, R.M. (1993): «Marketing de ciudades: La candidatura de Barcelona como sede olímpica». Harvard Deusto Business, ${ }^{\circ}$ 5, pp. 59-67.

AÑO, V., CALABUIG, F., AYORA, D., PARRA, D. y DUCLOS (2013): «Análisis sobre el grado de conocimiento e identificación de los tarraconenses con la candidatura a los Juegos Mediterráneos de Tarragona en 2017». Apunts, n 111, pp. 70-78.

ASHWORTH, G. y PAGE, S.J. (2011): «Urban tourism research. Recent progress and current paradoxes». Tourism Management, $\mathrm{n}^{\circ}$ 32, pp. 1-15.

AYUNTAMIENTO DE UTRECHT (2015): «Utrecht we all cycle». Disponible en http:// www.utrecht.nl/we-all-cycle/

BARCELONA TURISME (2014): «Estadísticas de turismo de Barcelona y comarcas». Disponible en http://professional.barcelonaturisme.com/imgfiles/estad/Est2014.pdf

BALDUCK, A.L., MAES, M., y BUELENS, M. (2011): «The social impact of the Tour of France: Comparisons of residents' pre- and post-event perceptions». European Sport Management Quarterly, $\mathrm{n}^{\circ} 11(2), \mathrm{pp} .91-113$.

BERRIDGE, G. (2012): «The promotion of cycling in London: The impact of the 2007 Tour de France Grand Depart on the image and provision of cycling in the capital». Journal of Sport \&Tourism, $\mathrm{n}^{\circ} 17(1)$, pp. 43-61.

BULL, C. y LOVELL, J. (2007): «The impact of hosting major sporting events on local residents: an analysis of the views and perceptions of Canterbury residents in relation to the Tour de France 2007». Journal of Sport \& Tourism, nº 12 (3.4), pp. 229-248.

CANADIAN SPORT TOURISM ALLIANCE (2014): «Value of sport tourism». Disponible en http://canadiansporttourism.com/industry-tools/value-sport-tourism.html

CARDENAL, M. (2016): «La Región de Murcia lo tiene todo para convertirse en una de las referencias del turismo deportivo». Disponible en http://www.mecd.gob.es/prensamecd/actualidad/2016/01/20160120-fiturcar.html

DAUNCEY, H. y HARE, G. (2003): The Tour de France: A pre-modern contest in a post-modern context, en DAUNCEY, H. y HARE, G. (Eds.) The Tour de France, 1903-2003: A century of sporting structures, meanings and values, pp. 1-29, Frank Cass, Londres.

DEPARTMENT FOR CULTURE, MEDIA \&SPORT (DCMS) (2015): A living legacy: 2010-2015 Sport policy and investment, DCMS, Londres.

EAPEN, I.S. (2014): «Sport tourism: Key drivers of tourism», Voyager's World, pp. 16-22. ERNST\&YOUNG (2014): «The economic impact of Rugby World Cup 2015». Disponible en http://www.ey.com/Publication/vwLUAssets/EY-rugby-world-cup-finalreport/\$FILE/EY-rugby-world-cup-final-report.pdf

FERNANDEZ ALLES, M. T. (2014): «El impacto turístico de los eventos deportivos: un estudio de caso». Cuadernos de Turismo, no 33 , pp. 59-76.

FOX, D., GOUTHRO, M.B., MORAKABATI, Y. y BRACKSTONE, J. (2014): Doing events research: From theory to practice, Routledge, Abingdon, Oxon.

GRATTON, C. y HENRY, I. (2001) (eds.): Sport in the city: The role of sport in economic and social regeneration, Routledge, Abingdon, Oxon. 
GETZ, D. (2003): «Sport event tourism: planning, development and marketing». Sport and Adventure Tourism, pp. 49-88.

GETZ, D. (2008): «Event tourism: definition, evolution and research». Tourism Management, $\mathrm{n}^{\mathrm{o}} 29.3$, pp. 403-428.

GIBSON, H.J. (1998): «Sport tourism: A critical analysis of research». Sport Management Review, $\mathrm{n}^{\circ} 1$, pp. 45-76.

GIBSON, H.J. (2003): «Sport tourism: An introduction to the special issue». Journal of Sport Management, $\mathrm{n}^{\circ} 17, \mathrm{pp} .205-213$.

GIBSON, H.J., QI, C. y ZHANG, J. (2008): «Destination image and intent to visit China, and the 2008 Beijing Olympic Games». Journal of Sport Management, $\mathrm{n}^{\circ}$ 22(4), pp. 427-450.

GIBSON, H.J. y FAIRLEY, S. (2014): Sport tourism, en PEDERSEN, P. y THIBAULT, L. (Eds.): Contemporary sport management ( $5^{\text {a }}$ Edición), Human Kinetics, Champaign, Illinois, pp. 264-288.

GREEN, C.B, COSTA, C. y FITZGERALD, M. (2008): Marketing the host city: Analizing exposure generated by a sport event, en WEED, M. (Ed.): Sport \&tourism: A reader. Routledge, Abingdon, Oxon, pp. 346-361.

HENDERSON, J.C, FOO, K, HERMES, L. y JIP, S. (2010) «Sports events and tourism: The Singapore Formula One Grand Prix». International Journal of Event \& Festival Management, $\mathrm{n}^{\circ} 1(1)$, pp. 60-73.

HENRY, I. y PARAMIO-SALCINES, J.L. (1999): «Sport and the analysis of symbolic regimes: A case study of the city of Sheffield». Urban Affairs Review, $\mathrm{n}^{\circ} 34(5)$, pp. 641-666.

HERSTEIN, R. y BERGER, R. (2013): «Much more than sports: sports events as stimuli for city re-branding». Journal of Business Strategy, $\mathrm{n}^{\circ} 34(2)$, pp. 38-44.

HIGHAM, J. (1999): «Commentary-sport as an avenue of tourist development: An analysis of the positive and negative impacts of sport tourism». Current Issues in Tourism, $\mathrm{n}^{\circ} 2$, pp. 82-90.

HIGHAM, J. (2005): Sport tourism destinations: Issues, opportunities and analysis. Elsevier, Londres.

HINCH, T. y HIGHAM, J. (2001): «Sport tourism: a framework for research». International Journal of Tourism Research, $\mathrm{n}^{\circ} 3$, pp. 45-58.

JIMENEZ MARTIN, P.J. (2011): Deporte y turismo. Fundamentos de gestión y organización, Síntesis, Madrid.

KAPLADINOU, K. y VOGT, C. (2007): «The interrelationship between sport event and destination image and sport tourists behaviours». Journal of Sport \& Tourism, $\mathrm{n}^{\circ} 12$ (34), pp. 183-206.

KAVARATZIS, M. (2004): «From city marketing to city branding: Towards a theoretical framework for developing city brands». Place Branding, $\mathrm{n}^{\circ} 1(1)$, pp. 58-73.

KITZINGER, J. (1994): «The methodology of focus groups: the importance of interaction between research participants». Sociology of Health \&Illness, $\mathrm{n}^{\circ}$ 16, pp. 103-121.

LAMONT, M. (2009): «Reinventing the wheel: A definitional discussion of bicycle tourism». Journal of Sport \& Tourism, $\mathrm{n}^{\circ} 14(1), \mathrm{pp}$. 5-23. 
LAMONT, M. y MCKAY, J. (2012): «Intimations of postmodernity in sports tourism at the Tour of France». Journal of Sport \& Tourism, n 17(4), pp. 313-331.

LATIESA, M. y PANIZA, J.L. (2006): « Turistas deportivos. Una perspectiva de análisis». Revista Internacional de Sociología, ${ }^{\circ}$ LXIV(44), pp. 133-149.

LAW, C.M. (2002): Urban tourism. The visitor economy and the growth of large cities. Cromwell Press, Trowbridge.

LEBLANC, J.M (2005): Tour de France, en ILLES BALEARS FORUM 2005. Building a working agenda in the field of sport and tourism, Nóos Institute, Baleares, pp. 73-74.

LLOPIS GOIG, R. (2004): Grupos de discusión. ESIC, Madrid.

LLOPIS GOIG, R. (Ed.) (2012): Megaeventos deportivos. Perspectivas científicas y estudios de caso. Editorial UOC, Barcelona.

LLOPIS GOIG, R. y GARCIA ALCOBER, M.P. (2012): La America's Cup regresa a Europa. Impacto socioeconómico de la $32^{\mathrm{a}}$ America's Cup en la sociedad anfitriona, en LlOPIS GOIG, R. (Ed.): Megaeventos deportivos. Perspectivas científicas y estudios de caso. Editorial UOC, Barcelona, pp. 155-174.

LOVELL, J. (2008): Post-modern heritage, chivalry, park and ride: Le Tour comes to Canterbury, en ALI-KNIGHT, J; ROBERTSON, M., FYALL, A. y LADKIN, A. (Eds.) International perspectives of festivals and events: Paradigms of analysis, Elseveir, Londres, pp. 265-277.

MASTERMAN, G. (2009): Strategic sports event management, Butterworth-Heinemann, Londres.

MINISTERIO DE EDUCACION, CULTURA Y DEPORTE (MECD) (2015a): Anuario de estadísticas deportivas 2015, Madrid, MECD.

MINISTERIO DE EDUCACION, CULTURA Y DEPORTE (MECD) (2015b): Encuesta de hábitos deportivos en España 2015, Madrid, MECD.

MORGAN, L.D. (1997): Focus groups as qualitative research (2 ${ }^{\mathrm{a}}$ Edición), Sage, Londres.

OFFICE FOR NATIONAL STATISTICS (2013): «Travel trend 2012». Disponible en http://www.ons.gov.uk/ons/rel/ott/travel-trends/2012/sty-visits-to-the-uk.html

PARAMIO SALCINES, J.L. (2001): El deporte como mecanismo de regeneración urbana en ciudades de la alta modernidad, en DEVIS, J. (Ed.) La educación física, el deporte y la salud en el Siglo XXI, Marfil, Valencia, pp. 229-244.

PARAMIO SALCINES, J.L. (2013): Sport and urban regeneration, en HENRY, I. y KO, L.M (Eds.) Routledge handbook of sport policy, Routledge, Abingdon, Oxon, pp. 275-288.

PEÑALVER TORRES, M. T. (2004): «El turismo activo como alternativa y complemento al modelo turístico en la Región de Murcia ». Cuadernos de Turismo, $\mathrm{n}^{\circ}$ 14, pp. 179-215.

ROBINSON, T. y GAMMON, S. (2004):«A question of primary and secondary motives: Revisiting and applying the sport tourism framework». Journal of Sport Tourism, n 9 (3), pp. 221-223. 
SANCHEZ, P., BARAJAS, A. y ALEN, M.E. (2013):«Los eventos deportivos como herramienta de promoción turística: Propuestas para el Rally de Ourense y su entorno». Revista de Análisis Turístico, no16(2), pp. 59-69.

SOCIAL RESEARCH ASSOCIATES (2007): «The Tour de France the Grand Depart 2007: Report to Transport for London». Disponible en http://content.tfl.gov.uk/tourde-france-research-summary.pdf

SMITH, A. (2008): Using major events to promote peripheral urban areas: Deptford and the 2007 Tour of France, en ALI-KNIGHT, J; ROBERTSON, M., FYALL, A. y LADKIN, A. (Eds.) International perspectives of festivals and events: Paradigms of analysis, Elseveir, Londres, pp. 3-20.

SMITH, A. (2010):«The development of "sport-city" zones and their potential values as tourism resources for urban areas». European Planning Studies, n 18(3), pp. 385-410.

SMITH, A. (2012): Events and urban regeneration. The strategic use of events to revitalize cities. Routledge, Abingdon, Oxon.

SCHUMACHER, D. G. (2015): «Report on the sports tourism industry». Disponible en https://www.sportscommissions.org/Portals/sportscommissions/Documents/Reports/ NASC\%20Sport\%20Tourism\%20Industry\%20Report.pdf

STANDEVEN, J. y DeKNOP, P. (1999): Sport tourism, Human Kinetics, Champaign, Illinois.

STATISTICS NETHERLANDS (2015): «Facts sheets: The Netherlands. Cycling country». Disponible en http://www.cbs.nl/NR/rdonlyres/9F9F3F71-9324-46D3-AD7E076C59F8392D/0/2015factsheetnederlandfietsland_ENG.pdf

UK SPORT (2015a): Major events investment guide. UK Sport, Londres.

UK SPORT (2015b): UK Sport major events investment guide. UK Sport, Londres.

VISIT BRITAIN (2015): «Football tourism scores for Britain. Inbound visitors that watch live football», $\mathrm{n}^{\circ} .141$, Septiembre. Disponible en https://www.visitbritain.org/sites/ default/files/vb-corporate/Documents-Library/documents/2015-9\%20VisitBritain $\% 20$ Report_Football\%20tourism\%20scores\%20for\%20Britain.pdf

WALLER, S., TRENDAFILOVA, S. y DANIELL, R. (2014): «Did the 2012 World Series positively impact the image of Detroit?: Sport as a transformative agent in changing images of tourism destination», Journal of Sport \& Tourism, nº19(1), pp. 79-100.

WEED, M. y BULL, C. (2004): Sport tourism: Participants, policy and providers, Routledge, Oxon.

WEED, M. (2008): Sport \&tourism: A reader, Routledge, Abingdon, Oxon.

WEED, M. (2009): «Progress in sports tourism research?. A meta review and exploration of futures». Tourism Management, $\mathrm{n}^{\circ}$ 30, pp. 615-628.

WICKER, P., HALLMANN, K. y ZHANG, J.J. (2012): «What is influencing consumer expenditure and intention to revisit? An investigation of marathon events». Journal of Sport \& Tourism, $\mathrm{n}^{\circ} 17$ (3), pp. 162-182.

ZUKIN, S., BASKERVILLE, M., GREENBERG, M., GUTHREAN, C., HALLEY, J., HALLING, M., LAWLER, K., NERIO, R., STACK, R., VITALE, A. Y WISSENGER, B. (1998): «From Coney Island to Las Vegas in the urban imaginary: Discursive practices of growth and decline». Urban Affairs Review, n 33, pp. 625-653. 


\section{AGRADECIMIENTOS}

Los autores agradecen la información facilitada e incorporada a la discusión del artículo por instituciones como el World Tourism Organization (OMT) con sede en Madrid, el Instituto de Turismo de España (TURESPAÑA) y la Subdirección General de Conocimiento y Estudios Turísticos. Agradecimientos que hacemos también extensibles a la directora de eventos del Club La Santa de Lanzarote, Isabelle Janssens de Varebeke por la información facilitada sobre el IRONMAN Lanzarote y, no menos importante, a los expertos que colaboraron en el grupo de discusión. 